\title{
Integrating road traffic externalities through a sustainability indicator
}

\author{
P. Fernandes ${ }^{a}$, $*$, M. Vilaça a , E. Macedo ${ }^{\text {a }}$ C. Sampaio a , B. Bahmankhah a , J.M. Bandeira \\ a, C. Guarnaccia b, S. Rafael c, A.P. Fernandes ', H. Relvas ', C. Borrego c, M.C. Coelho ${ }^{a}$ \\ ${ }^{a}$ Department of Mechanical Engineering, Centre for Mechanical Technology and Automation (TEMA), University of Aveiro, Campus Universitário \\ de Santiago, 3810-193 Aveiro, Portugal \\ ${ }^{\mathrm{b}}$ Department of Civil Engineering, University of Salerno, Via Giovanni Paolo II, 132, I-84084 Fisciano, SA, Italy \\ ${ }^{\mathrm{c}}$ Department of Environment and Planning, Centre for Environmental and Marine Studies (CESAM), University of Aveiro, Campus Universitário de \\ Santiago, 3810-193 Aveiro, Portugal
}

\section{ABSTRACT}

Road traffic poses negative externalities on society and represents a key challenge in sustainable transportation. However, the existing literature about the assessment of traffic externalities drawn on a common measure is scarce.

This paper develops a sustainability indicator that integrates traffic-related externalities as means of traffic congestion, noise, greenhouse gases (GHG) and nitrogen oxides emissions, health impacts and road crash related costs, and adjusted to local contexts of vulnerability.

Traffic, road crashes, acoustic and vehicle dynamic data were collected from one real-world intercity corridor pair comprising three alternative routes. The site-specific operations were characterized using a modeling platform of traffic, emissions, noise and air quality. A specific methodology is applied for each road traffic externality and translated in a single factor external cost.

The results indicated that road crashes presented the largest share in the partly rural/urban route while GHG emissions had the highest contribution in external costs for the highway routes. Also, the distribution of external cost component varied according to the type of road, mostly due to different levels of exposed inhabitants.

This paper offers a line of research that produced a method for decision-makers with a reliable and flexible cost analysis aimed at reducing the negative impacts of road traffic. It also encourages the design of eco-traffic management policies considering the perspective of drivers, commuters and population.

Keywords: Sustainability Indicator, External Costs, Road Traffic, Modeling, Traffic Externalities.

\section{INTRODUCTION AND RESEARCH OBJECTIVES}

Road traffic poses negative externalities on society, thereby representing one of the key challenges in sustainable transportation nowadays. In 2016, road transportation accounted for 
$73 \%$ and $83 \%$ of transportation greenhouse gases (GHG) emissions in the European Union (EU) (EEA, 2017b) and in the United States (US) (EPA, 2018), respectively. Long term-projections for carbon dioxide (CO2) emissions concerning the passenger transportation in cities of over 300 000 inhabitants show an increase up to 27\% in 2050 compared with 2015 levels (Chen and Kauppila, 2017).

Besides GHG emissions, road transportation has long-lasting negative impacts on road safety, human health and wellbeing. Road traffic crashes within EU claimed approximately 25,650 fatalities in 2016 (ERSO, 2018); 54\% of these occurred at rural roads (ERSO, 2018). Also, road transportation is one of the major sources of some harmful air pollutants such as particulate matter (PM), nitrogen oxides (NOX) and carbon monoxides (CO) (EEA, 2018a). Around 39\% of total NOX came from road transportation (EU member states), which represented the highest share of that gas in 2015 (EEA, 2017a). This sector is, by far, the dominant source of traffic noise in Europe, representing almost 90\% of total noise emissions (EEA, 2018b). Approximately 29 million living in main roads outside urban areas in EU-28 were exposed to average day-eveningnight noise levels (Lden) exceeding 55 dBA (EEA, 2018b). Traffic noise causes nuisance, stress reactions, sleep disturbance, and it also has negative effects on health, such as cardiovascular diseases (WHO, 2011).

Understanding the most cost-effective strategies to mitigate both traffic congestion and environmental related costs in road trips has been pointed out as one of the critical issues in transportation for the next 20 years (National Academies of Sciences, 2018). The overall size of transportation external costs is estimated at around 7\% of the EU Gross Domestic Product (EC, 2018). In this context, a more efficient use of existing infrastructure is essential to reduce road transportation externalities (EC, 2011).

However, there are some answered questions about the quantification of external costs namely:

- What would be the cost of a given route if drivers had to pay for their choices?

- Why would a driver have to choose the route with lowest emissions if local population could be at higher risk exposure to other traffic externalities?

- If drivers shift towards a fast route but with high traffic volumes and resulting pollutant emissions, then what would be the benefits in terms of overall costs compared to slower routes?

For this purpose, a simulation-based approach was conducted combining a methodology for estimating GHG (CO2 and Volatile Organic Compounds -VOCs), NOX and PM emissions, air quality (PM concentrations) and noise using a microscopic traffic simulation tool together with road crashes historical data in a real origin-destination (N-S and S-N) pair between Aveiro and Estarreja, Portugal. The location comprised three alternative routes, as follows: i) partly rural/urban; ii) low-traffic-volume highway with electronic pay tolls; and iii) high-traffic-volume highway with both conventional and electronic pay tolls. The proposed methodology allows to 
build a link-based sustainability indicator that can be updated in real-time through a set of information sources and translated into a monetary value.

This research intends to contribute for decision making by traffic management entities in the following aspects:

- To endow the current navigation platforms with reliable and flexible cost analysis which takes into account local-specific needs;

- To include other variables in order to assess their impact on the magnitude and share of traffic externalities according to the type of road;

- To encourage the design of eco-traffic management policies considering the perspective of drivers, commuters and population.

The remainder of the paper is organized as follows. Section 2 presents a review of scientific literature regarding the integration of road traffic externalities. In Section 3, the methodology for traffic, vehicular emissions, air quality and noise modeling, and calibration and validation of the simulation platform are presented, as well as the procedure for developing the proposed sustainability indicator. Section 4 describes the real-world intercity corridor, data collection and main modeling tasks. Subsequently, the results are used to assess the sustainable indicator in the candidate case study (Section 5). In all comparisons, the focus will be on range of each cost component value along routes, and potential trade-off among them. The final section outlines the main research findings and contributions and points out some future research needs (Section 6).

\section{LITERATURE REVIEW}

Internalizing the external costs of transportation has been an important concern for policy development and transportation research. According to Korzhenevych et al. (2014), internalization of transportation externalities can be based on quantifying in monetary values the associated impacts on society and environment, such as congestion, traffic noise, air pollution, greenhouse effects and road crashes. This degree of damage widely depends on the geographic conditions, intensity of traffic and population exposed (Yeh, 2013).

Negative externalities in the road transportation sector constitute an important development issue with socioeconomic costs (Cecchel et al., 2018) which are known to lead to welfare losses market inefficiencies (Kickhöfer and Kern, 2015). Usually, transportation users only account for marginal private costs, which may lead to welfare losses, since marginal social costs are neglected. To overcome such issues, some authors have been proposed to internalize the difference between generalized prices and marginal social costs by a tool [e.g. (Friesz et al., 2004; Small and Verhoef, 2007)]. However, they focused only on congestion effects. Road vehicles also give rise to side effects such as the productivity losses due to lives lost in road crashes, health costs caused by air or the abatements costs due to climate impacts (Bandeira et al., 2018a; Int Panis et al., 2004; Korzhenevych et al., 2014; Yeh, 2013). 
Despite its relevance, the existing literature about the assessment of traffic externalities drawn on a common measure (e.g., sustainability indicator) is scarce (Bandeira et al., 2014; El-Rashidy and Grant-Muller, 2015; Kickhöfer and Nagel, 2016; Sdoukopoulos et al., 2019; Torrao et al., 2016) and mostly focused in urban areas (Bandeira et al., 2018b; Sampaio et al., 2019; Tafidis et al., 2017; Yeh, 2013). Torrao et al. (2016) developed a safety, energy efficiency and green indicator based on crash consequences and type, and vehicle characteristics. The models neither accounted with impacts of changes in modal operation, nor included traffic volume as input. Kickhöfer and Nagel (2016) used an agent-based model to internalize air quality costs taking into account both traffic congestion and vehicle characteristics, but they focused only roads in urban areas.

Although rural roads represent $80 \%$ of the total road network length in developing countries (Rivera et al., 2015), the development of link-based indicators reflecting traffic-related impacts for this type of roads is little explored. El-Rashidy and Grant-Muller (2015) introduced a fuzzy logic model for assessing the mobility of road transportation networks. The model incorporated a physical connectivity attribute and traffic condition as mobility attributes and was successful tested for different intercity routes. Fernandes et al. (2018) analyzed the impacts of partialmetering strategies at a rural corridor near a shopping mall to reduce emissions, noise and user perspective costs. The proposed system resulted in improvements (up to 13\%) compared to the unmetered conditions. Recently, Chang et al. (2018) developed a road pricing model that integrated travel time, $\mathrm{CO} 2$ emissions and safety costs by combining them on a green safety indicator for evaluating the level of service in freeway traffic. However, the authors discarded impacts of local pollutants, such as PM.

Link-based indicators can be applied into advanced traffic management systems as vehicle routing problems, but existing literature around this topic is mostly focused on the use of empirical models for route choice optimization in urban areas (Ćirović et al., 2014; Jovanović et al., 2014; Pamučar et al., 2016a; Pamucar and Goran Ćirović, 2018; Pamučar et al., 2016b).

Thus, the following gaps in the literature review were revealed: i) none of the prior studies developed a sustainability indicator for integrating traffic externalities according to the road type, i.e., urban, rural and highway; ii) little is known about the impacts of site operational characteristics on each externality cost value; iii) few studies applied reliable methods for gathering the number of exposure people, who are directly affected to noise, NOX and PM.

The novelty of this research relies in the following aspects:

i) To use a simulation-based approach for quantifying and assessing external costs of road traffic at urban, rural and highway scales;

ii) To include a trade-off analysis among traffic externalities;

iii) To i VSP $=\mathrm{v} \times[1.1 \mathrm{a}+9.81 \sin (\arctan (\operatorname{grade}))+0.132]+0.00302 v^{3}$ mplement more effective eco-friendly and sustainable routing systems to include social, environmental and economic sustainable goals. 


\section{METHODOLOGY}

The core idea of the methodology was to use and test a modeling platform to evaluate external costs of road transportation at a segment level. It proceeded in five steps, illustrated in FIGURE 1. The development of the sustainability indicator involved first, collecting traffic volumes, noise, vehicle dynamic (second-by-second speed, acceleration and slope), crash data and population per unit square from one real-world intercity corridor. Second, the modeling platform was calibrated and validated, and then, studied location was divided into multiple sub-segments according to the road type. Finally, external costs of road transportation (Korzhenevych et al., 2014) were computed to obtain the sustainability performance measure in monetary values.

FIGURE 1 Overview of the research methodology (PGV - Passenger Gasoline Vehicles; PDV Passenger Diesel Vehicles; LCDV - Light Commercial Diesel Vehicles; HDV - Heavy Duty Vehicles; HCM - Highway Capacity Manual; VSP - Vehicle Specific Power; EMEP/EEA - European Monitoring and Evaluation Programme by European Environmental Agency; CONC Concentrations).

\subsection{Modeling Platform}

\subsubsection{Road Traffic Modeling}

VISSIM9.0 (PTV AG, 2016) (which stands for Verkehr In Städten SIMulationsmodell) was used to model road traffic operations, for four main reasons: 1) it allows setting several behavior parameters to reflect site-specific driving habits; 2 ) it accounts the variations in both vehicle speed and acceleration-deceleration profiles at rural and urban roundabouts and traffic lights, interchange ramps or conventional tolls (PTV AG, 2016); 3) it includes a calibration and validation of traffic-related metrics to set realistic representations of road traffic operations at urban (Fernandes et al., 2015), rural (Fernandes et al., 2018) and highway (Abou-Senna et al., 2013; Fontes et al., 2014; Fries et al., 2017) roads; 4) it exports vehicle dynamic and traffic volume (by vehicle type and segment-by-segment) data at high time resolutions that can be used by emission (Abou-Senna et al., 2013; Fernandes et al., 2015; Fontes et al., 2014), noise (Fernandes et al., 2018), and geo-processing tolls and air quality models (Borrego et al., 2016; Dias et al., 2018).

\subsubsection{Pollutant Emissions}

CO2 and NOX generated by Light Duty vehicles - LDV, i.e., PGV, PDV and LCDV were estimated using the VSP-based modeling approach that provides instantaneous vehicle power per unit 
mass (US EPA, 2002). This regression-based model is sensitive to changes in vehicle dynamic data and offers significant explanatory power for vehicle energy use and emissions rates IOVs (Hu et al., 2016). The use of VSP is justified because a speed-based approach as EMEP/EEA methodology, per se, is less robust to assess emissions of traffic singularities (roundabouts, traffic lights, toll plazas or stop-controlled intersections) and driving behavior states (acceleration, overtaking or gap acceptance) which in turn have impact on GHG and NOX external costs. VSP values are stratified into 14 bins, which in turn correspond to an emission factor on a second-by-second basis (US EPA, 2002). VSP is a function of speed, accelerationdeceleration and slope, as shown in Equation 1 for LDV (US EPA, 2002):

$$
\mathrm{VSP}=\mathrm{v} \times[1.1 \mathrm{a}+9.81 \mathrm{sin}(\arctan (\text { grade }))+0.132]+0.00302 v^{3},
$$

where $v$ is the instantaneous speed $(\mathrm{m} / \mathrm{s})$; a represents the instantaneous acceleration/deceleration $(\mathrm{m} / \mathrm{s} 2)$, and grade is the road slope (in decimal fraction).

Since VSP accounts for changes in vehicle dynamic with high resolution time, it shows as proper methodology for the quantification of exhaust emissions generated by PGV (Anya et al., 2013), PDV (Coelho et al., 2009), and LCDV (Coelho et al., 2009). A good body of literature has documented the effective use of VSP in assessing vehicular emissions in real-world urban, rural and highway routes (Anya et al., 2013; Coelho et al., 2009; Khan and Frey, 2018).

To obtain emissions estimates for HDV (CO2, NOX, VOCs and PM) and LDV (PM and VOCs), the EMEP/EEA method was used (EEA, 2013). It uses emission factors for diesel HDV from Euro I to VI emission standards and engine capacities as a function of the average speed (EEA, 2013). It must be stressed that EMEP/EEA is less robust to analysis emissions in traffic interruptions (e.g., roundabouts, toll plazas and traffic lights) that are characterized by high stop and go episodes (Coelho et al., 2014; Vicente et al., 2018). For instance, if this methodology was the only used, then the vehicular emissions would be underestimated.

A GUI application in MATLAB was conceived and developed to compute second-by-second LDV and HDV dynamics data from VISSIM output (speed, acceleration and slope). LDV and HDV emissions were summed up and further assigned to a segment. Then, such information incorporated on a GIS platform to assess pollutant concentrations, as described in the following section.

\subsubsection{Air Quality}

The air quality at the urban scale were evaluated by applying the air quality modeling system URBan AIR (URBAIR) (Borrego et al., 2014; Valente et al., 2014). The URBAIR model is an improved version of the second generation Gaussian model POLARIS developed by Borrego et al. (1997), differing from traditional Gaussian dispersion models in what concerns its dispersion parameters, which have a continuous variation with the atmospheric stability, and it accounts for building-induced dispersion mechanisms. 
This steady state atmospheric dispersion model is based on boundary layer scaling parameters and is suitable to be used for distances up to about $10 \mathrm{~km}$ from the source. The URBAIR modelling system is designed to be modular and includes the pre-processing of land use and urban elements geometry (GIS-based), meteorological conditions and air pollutant emissions, coupled with a dispersion module. The system framework is designed in such a way that the inputs/outputs of the different modules are shared and linked along the modeling process.

The meteorological model calculates a set of meteorological parameters, such as atmospheric turbulence characteristics, mixing height, friction velocity, Monin-Obukhov length and surface heat flux, using as initial conditions, or measured data. Since the topography and build-up structure characteristics have a significant influence on the dispersion of atmospheric pollutants, particularly in urban areas, URBAIR also requires characterization of the spatial variation of terrain surface elevation, buildings 3D coordinates and roads 2D coordinates. For simplicity, buildings can be assembled based on proximity and geometry criteria.

URBAIR considers different types of source emissions, namely, area, volume, point (such as industrial facilities and combustion activities for residential and services sectors) and line sources (road traffic emissions). As outputs, URBAIR provides air quality patterns for a given spatial domain (with up to about $50 \mathrm{~km}$ from the domain center) and time period (e.g., hourly, daily, one year or multiple years) for different air pollutants, namely: PM10, Nitrogen dioxide (NO2), Sulfur dioxide (SO2) and $\mathrm{CO}$.

URBAIR model has been widely applied and extensively tested, having showed capability to produce robust and realistic results. Recent works showed its usefulness and capability to perform air quality studies at urban scale (Borrego et al., 2016; Dias et al., 2018).

In this study, URBAIR model was selected for two main reasons: 1) it is designed to assess the impact of urban planning and traffic management on air quality; 2 ) it is an advanced Gaussian model that has been enhanced with several major features, mainly the treatment of road traffic emissions and 3D urban elements.

\subsubsection{Noise}

The prediction of noise levels was made using a numerical approach developed by Quartieri et al. (2010). This procedure relates directly the acoustical energy sent to a receiver to the number of vehicles, to the source-receiver distance and to the mean traffic speed. The above information is used to assess source power levels and then, equivalent noise levels for a particular segment $k$ (Leq, $k$ ), which are obtained at a fixed distance $d$, according to the distance between the road axis and the receiver. Equation 2 gives the hourly equivalent noise level by segment (Guarnaccia, 2013):

$$
L_{e q, k}=10 \log \left(V_{L D V}+n V_{\text {HDV }}\right)+53.6+26.8 \log v_{k}-20 \log d-46.563 \text {, }
$$


where Leq, $k$ is the segment-specific equivalent noise level (dBA); VLDV and VHDV are the hourly LDV and HDV, respectively, volumes (vph); $n$ represents the acoustic equivalent, i.e., the number of LDV that produce the same noise of a HDV; vk is the segment-specific average speed $(\mathrm{km} . \mathrm{h}$ 1); $d$-Distance between the road axis and the receiver $(m)$ (Quartieri et al., 2010).

The advantage of this type of semi dynamic noise model is that only information about vehicle speed and traffic volumes for a given segment is needed. This means that there is no need of new noise equation for every other region or country.

To obtain day-evening-night level (Lden,k) on a segment $k(d B A)$, the hourly segment-specific equivalent level (Leq, $\mathrm{K}$ ) was assumed to be the same during all day. This is a conservative assumption since during the night traffic noise is usually lower than during daytime (EEA, 2018b). Thus, Lden was computed using Equation 3:

$$
L_{d e n, k}=10 \log \left[\frac{1}{24}\left(12 \cdot 10^{\frac{L_{e q, k}}{10}}+4 \cdot 10^{\frac{L_{e q, ~}+5}{10}}+8 \cdot 10^{\frac{L_{e q, ~}+10}{10}}\right)\right] \text {, }
$$

\subsubsection{Calibration and Validation}

The modeling platform was calibrated and validated using field data collected from the studied location. The data were divided in training (70\%) and testing (30\%) sets (Liu et al., 2017), randomly selected before calibration procedure. The following strategy was used:

- Capacity Calibration - Simulated and observed traffic volumes were compared for each monitoring point. The stopping criterion for this step was: at least $85 \%$ must meet the criteria of GEH (acronym for Geoffrey E. Havers) < 4 (Yu and Fan, 2017);

- Route Choice and Noise Calibration - Simulated travel time per each route as well as noise were compared against the training data. The procedure stops when the difference in sample mean was not statistically significant within a $95 \%$ confidence level ( $p$-value < 0.05);

- $\quad$ Route Choice and Noise Validation - Site-specific simulated and testing set of travel time and noise were compared with 10 random seed runs (Winnie et al., 2014).

\subsection{Sustainability Indicator}

The proposed sustainability indicator is intended to account monetary costs per vehicle (€.veh1) from road transportation activities in terms of: 1) congestion; 2) noise; 3) GHG; 4) NOX; 5) health impacts; and 6) road crashes. The following paragraphs describe in detail each cost component calculations.

\subsubsection{Traffic Congestion}


For a given segment, depending on the road type, congestion level is represented by the volumeto-capacity ratio defined as $\mathrm{V} / \mathrm{C}$, where the volume $\mathrm{V}$ is the mixed traffic (expressed in passenger car units per hour - pcu.h-1 per lane length) which takes into account HDV adjustment factors as suggested by the Highway Capacity Manual Sixth Edition (HCM, 2016), and the capacity C is the theoretical maximum traffic volume along segment which is estimated according to the type of facility (HCM, 2016), as follows:

Urban and Rural Segments - 1600 pcu.h-1 per lane;

Highway Segments -2500 pcu.h-1 per lane;

Weaving, On-ramp, Off-ramp and Basic Segments -2200 pcu.h-1 per lane (HCM, 2016).

Each segment-specific $\mathrm{V} / \mathrm{C}$ ratio results in five congestion levels, as follows (Korzhenevych et al., 2014): 1 (free-flow) $-\mathrm{V} / \mathrm{C}<0.25 ; 2-$ if $0.25<\mathrm{V} / \mathrm{C}<0.50 ; 3-0.50<\mathrm{V} / \mathrm{C}<0.75 ; 4$ (near capacity) $-0.75<\mathrm{V} / \mathrm{C}<1 ; 5$ (over capacity) V/C $>1$. Each level is then, associated to a congestion cost (CCk) on a segment that can be adjusted to the local conditions, road type and vehicle type (Korzhenevych et al., 2014), as given by Equations 4 to 7:

$$
\begin{aligned}
& T C_{k}=\frac{C_{L D V} V_{L D V}+C_{H D V} V_{H D V}}{V_{L D V}+V_{H D V}} I_{k}, \\
& C_{L D V}=f\left(\frac{V}{C}\right), \\
& C_{H D V}=f\left(\frac{V}{C}\right), \\
& L_{i}=f\left(\frac{V}{C}\right),
\end{aligned}
$$

where TCk is the traffic congestion cost on a segment $\mathrm{k}$ (€.veh-1); cLDV and cHDV are the local congestion costs for LDV and HDV, respectively, depending on the V/C according to the type of road (urban, rural and highway) ( $€ /$ veh. $\mathrm{km}$ ); $\mathrm{lk}$ is the length of the segment $\mathrm{k}(\mathrm{km})$; and $\mathrm{Li}$ is the level of congestion, which also depends on the $V / C(i=1, \ldots, 5)$.

\subsubsection{Noise}

The approach for estimating segment-specific noise costs is based on the cost of noise in $€ / d B A$ per exposed person and per hour of the local population potentially exposed to a certain noise range considering the LDV and HDV traffic in kilometers traveled, as given by Equation 8: 


$$
N_{k}=\frac{C L_{d e n, k} p o p_{k}}{a b\left(V_{L D V}+V_{H D V}\right) I_{k}}
$$

where $N k$ is the noise cost on a segment $k$ ( $€$.veh-1); CLden, $k$ is the cost of a given day-eveningnight noise level Lden, $\mathrm{k}(€ / \mathrm{dBA}$ per person and per year) adjusted to the local conditions and type of road (Korzhenevych et al., 2014); popk is the number of individuals potentially exposed to the noise level Lden, $\mathrm{k}$ (inhabitants per km of segment length) that is represented by local population; and $a$ and $b$ are equal to 365 (number of days) and 24 (number of hours), respectively.

\subsubsection{GHG}

In this paper, $\mathrm{CO} 2$ and VOCs emissions were considered for the cost quantification related with the impact of GHG on environment, human health and economy. The cost estimation procedure involved three steps: 1) to compute emissions to the overall network according to the share of LDV and HDV; 2) to assign emissions to a segment; 3) to calculate segment-specific emission costs based in the costs provided in using Equation 9:

$$
G H G_{k}=\alpha_{1}\left(\frac{\sum_{j=1}^{5} \sum_{i=1}^{N_{K}} v_{j} e f_{C O_{2}, j, i, k}}{V_{L D V}}+\frac{E_{C O_{2}, H D V, k}}{V_{H D V}}\right)+\alpha_{2}\left(\frac{E_{V O C s, L D V, k}}{V_{L D V}}+\frac{E_{V O C s, H D V, k}}{V_{H D V}}\right),
$$

where GHGk is the GHG cost on a segment $k$ ( $€$.veh-1); $\alpha 1$ is the local damage cost of CO2 (Korzhenevych et al., 2014) (€.g-1); vj is the share of the vehicle type $\mathrm{j}$ in the LDV vehicle park fleet; efCO2, j, $k$ is the $\mathrm{CO} 2$ emission factor vehicle type $\mathrm{j}$ in the second of travel $\mathrm{i}$ on segment $\mathrm{k}$ (g.s-1); ECO2, HDV, k represents the HDV CO2 emissions on a segment k (g.s-1); Nk is the travel time on segment $\mathrm{k}(\mathrm{s}) ; \alpha 2$ is the local damage cost of VOCs (Korzhenevych et al., 2014) (€.g-1); EVOCs, LDV, k represents the LDV VOCs emissions on a segment $k$ (g.s-1); and EVOCs, HDV, $k$ represents the HDV VOCs emissions on a segment k (g.s-1).

\subsubsection{NOX}

The quantification of NOX costs accounts for the impacts on local population which is represented by the ratio between segment population and national population densities, as given by Equation 10: 


$$
N O_{x k}=\beta \frac{D_{k}}{D_{N}}\left(\frac{\sum_{j=1}^{5} \sum_{i=1}^{N_{k}} v_{j} e f_{N O_{x}, j, i, k}}{V_{L D V}}+\frac{E_{N O_{x}, H D V, k}}{V_{H D V}}\right),
$$

where NOXk is the NOX cost on a segment $k(€$.veh-1); $\beta$ is the local damage cost of NOX (Korzhenevych et al., 2014) (€.g-1); Dk is the number of individuals for segment $k$ per square kilometer; DN is the national population density; efNOX, j, k is the NOX emission factor vehicle type $\mathrm{j}$ in the second of travel i on segment $\mathrm{k}$ (g.s-1); and ENOX, HDV, $\mathrm{k}$ represents the HDV NOX emissions on a segment $k$ (g.s-1).

\subsubsection{Health Impacts}

Currently, it is well known that air pollution, mainly by the form of particles with an aerodynamic diameter smaller than $10 \mu \mathrm{m}$ (PM10), is an important incentive for the development and exacerbation of respiratory diseases, such as asthma, chronic obstructive pulmonary disease or lung cancer, as well as a substantial impact on cardiovascular disease (Costa et al., 2014; Rückerl et al., 2011).

The evaluation of the health cost linked to the health impacts can be performed by multiplying the Years of Life Lost (YOLL) value by its associated economic value. Vlachokostas et al. (2012) suggest the average value of $52000 €$ by YOLL. Based on the achieved air quality state for a specific situation, the health impact cost on a segment k, related with PM10 on an hourly basis may be computed using Equation 11:

$$
H I_{k}=52000 \frac{C F R \text { pop }_{30 k} c_{k}}{a b\left(V_{\text {LDV }}+V_{\text {HDV }}\right)},
$$

where HIk represents the health impacts cost on a segment $k$ (€.veh-1); CRF is the correlation coefficient between the PM10 concentration variation and the probability of experiencing or avoiding a specific health indicator, which was set to $0.0004 \mathrm{YOLL} /$ (person.year. $\mu \mathrm{g} . \mathrm{m}-3$ ) (EC, 2006); pop30,k is the number of individuals potentially exposed over 30 years (inhabitants per $\mathrm{km}$ of segment length); and ck is the average PM10 concentration on a segment k ( $\mu \mathrm{g} \cdot \mathrm{m}-3$ ).

\subsubsection{Road Crashes}

The level of external crash costs depends not only on the crash severity, but also on the insurance system, i.e., social costs of traffic-related crashes (Korzhenevych et al., 2014). These costs can be obtained by applying an adjusted risk that involves the following cost components: i) death and injury due to an accident for the person exposed to risk; ii) for the relatives and 
friends of the person exposed to risk; and iii) crash cost for the rest of the society. These considerations are summarized in Equation 12:

$$
R C_{k}=\frac{X_{F} S C_{F}+X_{S I} S C_{S I}+X_{L I} S C_{L I}}{a b\left(V_{L D V}+V_{H D V}\right) I_{k}},
$$

where RCk is the road crash cost on a segment $k$ ( $€$.veh-1); XF, XSI, XLI are the annual numbers of fatalities, serious and light injury cases, respectively, on a segment k; and SCF, SCSI, SCLI represent the average social accident costs $(€)$ for crashes involving fatalities, serious and light injuries, respectively, adjusted to local conditions.

\subsubsection{External Cost by segment and by route}

The total external cost on a segment $\mathrm{k}$ is defined as the sum of the above cost components for a segment, and denoted as ECk (€.veh-1), as expressed by Equation 13:

$$
E C_{k}=T C_{k}+N_{k}+G H G_{k}+N O_{X k}+H I_{k}+R C_{k} .
$$

Lastly, the external cost associated to a route $r$ for a specific travelling direction, here denoted by $\mathrm{ECr}$ ( $€$.veh-1), is the sum of costs for all segments $\mathrm{kMr}$, where $\mathrm{Mr}$ is the set of segments along the route $r$, along that path, as given in Equation 14:

$$
E C_{r}=\sum_{k \in M_{r}} E C_{k}
$$

\section{CASE STUDY}

An origin-destination (South to North; North to South) pair, comprising three parallel alternative routes, was sought out for this research. Prior research carried out in this area have shown that road type has impact on pollutant emissions (Bandeira et al., 2013). This intercity corridor provides a direct connection between Aveiro and Estarreja (Portugal) and is near a high-density industrial complex with moderate HDV traffic; hence, the air quality and traffic-related noise can represent an important issue, especially for local population. These routes were chosen based on their different specificities. The routes include urban (with speed (s) limits in the range $0 \leq \mathrm{s}$ $\leq 50 \mathrm{~km} / \mathrm{h}$ ), rural $(50 \leq \mathrm{s} \leq 90 \mathrm{~km} / \mathrm{h}$ ) and highway $(90 \leq \mathrm{s} \leq 120 \mathrm{~km} / \mathrm{h}$ ) trip sections (FIGURE 2-b). R1 is partly conducted on a rural (63\%) and urban (37\%) roads, while R2 is mostly a low-trafficvolume section (75\%) traversing A29 highway, which has 2 lanes on each direction and an electronic pay toll system. Approximately $65 \%$ of R3 is on a high-traffic-volume section along A1 highway, with 2 lanes on each direction, and it includes both conventional and electronic pay 
toll systems. Average daily traffic (ADT) on A1 and A29 study segments is about 39950 and 11 700 , respectively (IMT, 2019). It must be noted that the classification of roads was based on posted speed limits and also on population density (Korzhenevych et al., 2014).

FIGURE 2 Study Domain: a) Routes Aerial View; b) Type of Road; c) Data Monitoring Points. Background Map Source [Open Street Maps].

\subsection{Data collection}

Traffic data were collected in morning (7:00AM-10AM), off-peak (11AM-2PM) and evening peak (5PM-7PM) during six typical weekdays in May and June 2018 under dry and windless weather. Traffic volume manual counting was performed in 15-min time intervals (in both travelling directions) at specific sites and video cameras were used to collect intersection-specific demand and turning split distributions. ADT volumes for A1 and A29 highways were retrieved from the Institute for Mobility and Transport (IMT, 2019), and complemented with the available images of video cameras installed at the top of highway bridges. A total of 42 monitoring points (including intersection entry and exit points) were evaluated in the studied location, allowing an accurate assignment of road traffic along the overall network.

Sound pressure levels were measured using an integrating sound level meter RION-NL52 (0.1-s basis) installed in 14 locations points of the study network, as depicted in FIGURE 2-c. To account for variability in noise values, tests were conducted in cruise speed (N2/N3), acceleration (N1/N4/N6/N9) and highway (bridges - N10/N11/N13/N14; wayside - N12) points. The microphone was in the acoustic field at $1.5 \mathrm{~m}$ from the ground (height of tripod) and at $7.5 \mathrm{~m}$ and $15 \mathrm{~m}$ from the main road axis in R1 and R2-R3, respectively. More than 50 data sets of 15min (equivalent continuous sound level - Leq and respective arterial traffic) were collected.

Six routes across the study domain were covered using GNSS data-logger and On-Board Diagnostic (OBD-II) system in nine equipped LDV (gasoline and diesel) and six different drivers to record vehicle speed in 1-s interval. These routes are defined as follows: i) North to South (R1); ii) South to North (R1); iii) North to South (R2); iv) South to North (R2); v) North to South (R3); vi) South to North (R3). Prior to on-road dynamic tests, the minimum number of travel time trips was determined for each route. Thus, taking into account the ADT observed in R2 [vehicles per lane <15 000 (IMT, 2019)] and R3 [15 000<vehicles per lane<20 000 (IMT, 2019)] and traffic signal density (<3TL/1.6 km) in R1, the minimum sample size is 8 (Turner, 1998). Almost 1300 $\mathrm{km}$ of road coverage data over the course of $22 \mathrm{~h}$ were collected ( 90 GNSS travel time trips -15 per route).

Air quality within the study area was estimated for a simulation domain defined over the road traffic network, with dimensions of $13 \times 16 \mathrm{~km} 2$, as shown in FIGURE 2-b. Since the road traffic emissions have been calculated with a high level of detail, a mesh resolution of $20 \times 20 \mathrm{~m} 2$ have been used (in a total of 717213 cells). Road traffic emissions were estimated following the 
methodology described in Section 2.1.2. The contribution of industrial areas and point sources inside the domain (e.g., some bakeries using wood burning ovens or residential combustion), were accounted as suburban background. The URBAIR domain covers the densely urbanized areas near the road network (located in a radius of $5 \mathrm{~km}$ from the highway road) allowing for the calculation of the health impacts. According to the methodology described in Section 2.2.5, the simulations were carried out for PM10.

Crash data involving motor vehicles along R1, R2 and R3 were gathered for 3-years' time period between 2015 and 2017 (ANSR, 2017). This period was selected for two main reasons: 1) A29 highway had no tolls until September 2010. After tolls introduction, the segment traffic dropped more than half (IMT, 2011); 2) lack of precise GPS coordinates before 2015 in order to assign to a specific segment. For the purpose of this study, crashes involving motor vehicles involving injuries and/or fatalities were selected and georeferenced on ArcGIS 10.5.0.6491 (ERSI, 2016). The database covered a total of 68 crash observations.

\subsection{Case Study Coding}

Posted speed limits along the study domain and gap acceptance (critical and follow-up headways) in roundabout approaches were considered taking into account local driving habits (Vasconcelos et al., 2013). The dwell time distribution at conventional pay tolls was assumed to be same for all gates (6.8-9.6 s) (Coelho et al., 2005). The simulation runs lasted 90 minutes with a 30-min warm-up period to load traffic onto the road network. The simulation network in VISSIM is exhibited in FIGURE 2.

CO2 and NOX emission rates for LDV were based on a local car fleet (EMISIA, 2017): 39\% (1.4L: $33 \%, 1.8 \mathrm{~L}: 5.95 \%, 2.2 \mathrm{~L}: 0.05 \%)$ LDGV, $40 \%$ LDDV (1.9L), and 21\% LDDT (2.5L). Since the terrain is flat in the study area, the effect of slope (Equation 1) was ignored.

Concerning the EMEP/EEA methodology, the least squares fitting technique was used to find the data best-fitting curve to relate segment-specific average speed and emissions generated by local HDV and LDV taking into account the above car fleet composition (EMISIA, 2017) and considering representatives vehicles and their emission standards, the annual activity (vehicle kilometers traveled per year), and engine size and capacity of the vehicle. Bus activity was also ignored since it represented less than $1 \%$ of corridor-specific traffic.

\subsection{Segments Definition}

The study domain was divided into multiple segments to compute each cost component and associated external cost by route. This level of segmentation was motivated by differences in type of road, downstream traffic control treatment, traffic volumes, number of crashes and number of lanes. The proposed segmentation is exhibited in FIGURE 3 a-c and includes each travelling direction. To account the number of individuals potentially exposed (popk), the 
population density per square kilometer along the study domain (Statistics of Portugal, 2018) was used. For the purpose of the analysis, popk was computed based on the percent of segment within each square in FIGURE 4. TABLE 1 describes segment-specific information, including corresponding route and type of road.

FIGURE 3 Segments definition by route: a) R1: b) R2; c) R3. Background Map Source [Open Street Maps].

TABLE 1 Key characteristics of proposed segments.

FIGURE 4 Local population density per square kilometer (Statistics of Portugal, 2018). Source [ArcGIS].

\subsection{Marginal cost factors}

The marginal cost factors for the proposed sustainability indicator defined in Section 2.2 are presented in TABLE 2 and TABLE 3 for congestion and noise components, respectively, according to the site-specific conditions. These values, provided in Korzhenevych et al. (2014, are used to express transportation externalities into monetary terms for road trip sections in Portugal (year 2010). Concerning the emissions and road crashes, the following values were adopted (Korzhenevych et al., 2014): c1 = 9×10-5 €.g-1; c2 = 1 048×10-6 €.g-1; c3 = 1 957×10-6 €.g-1; SCF $=1505000 € ; \mathrm{SCSI}=210000 € ;$ and SCSI = $13800 €$. The population density (DN) was 112 inhabitants per kilometer square (Statistics of Portugal, 2018).

TABLE 2 Marginal cost factors for congestion according to the type of road (Korzhenevych et al., 2014).

TABLE 3 Marginal cost factors for noise exposure (Korzhenevych et al., 2014).

\section{RESULTS AND DISCUSSION}

In this section, the main results from the field data are analyzed (Section 4.1) followed by the calibration and validation of the modeling platform (Section 4.2), and finally, a representation of the external costs for the studied location is presented (Section 4.3).

\subsection{Field Data}

The analysis of field data suggested the peak hour occurred between 5:30-6:30PM. Thus, such period was selected for the assessment of road transportation external costs. 
The hourly traffic volumes distribution (both travelling directions) along the study domain is shown in FIGURE 5. The number of vehicles in R1 ranged from 922 to $1108 \mathrm{vph}$ on rural roads. The difference in the number of vehicles on urban area (from 1276 to $780 \mathrm{vph}$ ) was due to the fact that a portion of traffic diverted from R1 to the downtown city center. Field results suggest that the R3 traffic volumes are three times higher than R2 values. This happens because R3 serves through-traffic between Northbound and Southbound, and it is the main interchange for Eastbound-Westbound traffic. It is worth to notice that HDV represented nearly 3\%, 4\% and $9 \%$ of R1, R2 and R3 traffic composition, respectively, in the studied location.

FIGURE 5 Traffic Volumes between 5:30-6:30PM. Background Map Source [Open Street Maps].

FIGURE 6 depicts the spatial distribution of 68 crashes, which took into account the level of injury severity (95 light injuries; 1 serious injury and 1 fatality). Several conclusions about the crash database can be drawn: 1) approximately $47 \%$ of crashes occurred in rural trip sections which corresponds to $42 \%$ of the travel distance across the corridor; 2 ) albeit short, urban section had 11 crashes involving motor vehicles, which was about $16 \%$ of crash occurrences in only $6 \%$ of overall study domain length; 3) $49 \%$ and $37 \%$ of light injuries were observed in highway and rural trip sections, respectively; 4) R1 had both the highest number of crash observations (41) and highest number of light injuries (47), and it also recorded one fatal crash; and 5) main blackspots were located in influence area of roundabouts and traffic lights along R1 (e.g., segments 2-17, 3-16, 4-15 and 8-9) and R3 highway trip sections (e.g., segments 9-20).

FIGURE 6 Spatial distribution of crashes based on level of injury severity: a) Light injury: b) Serious Injury; and c) Fatality. Background Map Source [Open Street Maps].

\subsection{Calibration and Validation}

The statistical indicators of the modeling platform showed solid results. For traffic, the calibration target suggested in the literature was accomplished, i.e., GEH was lower than 4 in 39 out of 42 monitoring points (93\%) (Yu and Fan, 2017). It should be emphasized that HDV traffic distributions were used in the traffic modeling.

The comparison of simulated and training travel time was performed using 30 floating car runs. The relative difference in average travel time was lower than $5 \%$ ( $p$-value $>0.05$, and thus, not statistically significant), as shown in TABLE 4. During calibration, vehicle speed distributions, critical headways at roundabouts, and green times and cycle length at traffic lights were adjusted to fit travel time data. The comparison of testing and estimated travel time sets also demonstrated good degree of consistency (1-6\%, depending on the route); no route showed significant differences at a $95 \%$ confidence level ( $p$-value between 0.10 and 0.67 ).

TABLE 4 Summary of Calibration and validation of travel times. 
It was also found that the noise estimates using the proposed methodology (Quartieri et al., 2010) matched the field measurements (training test). Under high noise values, the model tends to overestimate experimental data. This happens because field measurements taken at bridges end up being affected by a screening due to the bridge itself, even considering diffraction, i.e., noise emitted by vehicles outside the viewing angle of sound level meter. The predicted coefficient of determination (R2) was almost $80 \%$ for simulated Leq using a linear regression analysis (FIGURE 7a-b). An identical trend was observed for noise validation (testing set fit simulated data in $84 \%)$.

FIGURE 7 Noise methodology: a) Calibration; b) Validation.

\subsection{External Costs}

This section presents the main results regarding external costs associated to the road traffic with existing conditions. The sum of each segment costs (EC) along each route confirmed $R 2$ as the best option for the study domain (FIGURE 8 a-f). For instance, if one driver chooses R2 from south to north direction, then one could save $28 \%$ and $32 \%$ in external costs when compared with R1 and R3, respectively. Since vehicles were subjected to stop-and-go situations at conventional pay tolls (impact on emissions as demonstrated by Coelho et al. (2005) together with moderate traffic volumes in some of its segments, high external costs were observed for R3. For instance, segment with pay tolls accounted for approximately $10 \%$ of route external costs.

The analysis of the distribution of cost components along R1 showed the largest share corresponded to the RC-related costs; they represented around $31 \%$ and $30 \%$ of external costs in south-north and north-south directions, respectively. GHG showed as the largest contributor to external costs (40-45\%, depending on travelling direction) in R2. For the latter route, results indicated the share of RC in south-north direction (16\%) was higher than in north-south (9\%). This happened because one crash involving a serious injury was recorded in segment 4, resulting thus in high social costs (see Section 3.4 for those details). Almost half of external costs along R3 were based on GHG emissions, and more than $18 \%$ based on NOX. This was due to the fact HDV traffic is relevant in that route. In turn, other externalities ( $\mathrm{HI}$ and TC) had slight impacts.

FIGURE 8 Distribution of external costs by route: a) South to North (R1); b) North to South (R1); c) South to North (R2); d) North to South (R2); e) South to North (R3); f) North to South (R3).

The distribution of cost components differed from the type of road (FIGURE $9 \mathrm{a}-\mathrm{c}$ ). The highest share of external costs per vehicle, which was about $33 \%$ of traffic-related costs in urban sections, was due to noise generated by road traffic. This happened because $\mathrm{N}$ is very sensitive to changes in potentially exposed population, which is clearly high in urban segments. Albeit small, NOX and PM10 represented together $35 \%$ of costs in urban areas thereby, reflecting its impacts on local population. The findings from rural sections suggested a different trend (GHG 
accounted for $33 \%$ of external costs, followed by RC, with $30 \%$ ). Concerning the highway, it is interesting to note that GHG represented around $74 \%$ of the external costs, while $\mathrm{N}$ and NOX had small impacts ( $10 \%$ each). From FIGURE 9, and as expected, traffic congestion had a small expression in external costs regardless of the type of road, which can be explained by the level of congestion along the study domain ( $\mathrm{Li}<4)$ (Korzhenevych et al., 2014).

FIGURE 9 Distribution of external costs by type of road: a) urban; b) rural; c) highway.

FIGURE 10 a-c exhibits the hotspot costs (TCK) location by segment and route. Analysis results showed links with highest costs (red color) were found in segments 2-17 of R1, segments 5-12 of R2 and segments $9-20$ of R3. They represented nearly $27 \%, 39 \%$ and $28 \%$ of the R1, R2 and R3 total costs, respectively. The different colors observed in North-South and South-North directions along R2 and R3 was due to the difference in the number of crashes. Rural segments had high costs contributing thus with $62 \%$ of total costs along R1, which was mostly explained by the number of crash observations and resulting injury severity at those segments.

FIGURE 10 Distribution of external costs by segment: a) R1; b) R2; c) R3.

The learning gained from the test of the proposed sustainability indicator in the real-world case study is promising, which makes possible its integration in current eco-routing systems using the methodology of this paper and apply it to any route. The sustainability indicator was capable of reflecting each externality weight in costs and identifying trade-off concerning the selection of different routes with different purposes. On the one side, if drivers are guided to a route with less GHG emissions, they can be guided to roads with higher noise or air quality levels, confirming thus, the relevance for a quantification of potential population exposure. On the other side, a faster route (e.g., R3) may not represent lower external costs when compared to a slower one, emission and road crashes costs could be significant in some of its stretches when levels of traffic flows are significant. In these circumstances, the eco-routing information should be provided for ensuring both marginal private and social costs.

\section{CONCLUSIONS}

.The integration of road traffic impacts in one single indicator was one major drawback for the use of advance traffic management systems for estimating external costs. This paper developed a sustainability indicator for quantifying traffic externalities as means of traffic congestion, noise, GHG, NOX, health impacts and road crash related costs. The proposed methodology was tested in a commuting corridor with three main alternative routes.

Low-traffic-volume highway yielded $28 \%$ and $32 \%$ lower external costs than other routes. Road crash costs presented the largest share along the partly rural/urban route while GHG costs were most significant in routes with highway trip sections. For the road-level analysis, some 
differences in the distribution of external costs can be highlighted. The share of noise and NOX in external costs were only significant in urban roads mostly due to higher potentially exposed population in those areas.

This research has both scientific and societal contributions. Regarding the scientific contribution, it allows incorporating other variables to assess their impact on the magnitude and share of traffic externalities according to the type of road. Some of these include the variation in the number of circulating lanes, posted speed limits, traffic control treatment design, emission limit values, car fleet distributions or meteorological forecasts. Regarding the societal contribution, it allows endowing current navigation platforms with reliable and flexible cost analysis that accommodate local-specific needs and encouraging the design of eco-traffic management policies considering the perspective of drivers, commuters and population. For instance, this methodology can be embedded in the transportation infrastructure to enable authorities to identify and prevent polluting or noisy vehicles from entering in sensitive areas, thus reducing the effects of the non-respect of tolerance limits. Other societal contribution is the support of future road pricing schemes that include a given cost value related with road traffic externalities.

Undoubtedly, given the complexity of the proposed integrated approach, which alludes to areas of large-size transportation modeling, short time analysis, pollutant emissions, noise and concentrations calculations, potentially population affected to some traffic externalities, and size of crash database, several simplifications were made. These, in turn, yield three main limitations of the paper. First, on-road exposure can reach a substantial share in noise, NOX and heath impact costs, but the approach in this paper assumed a fixed value (local population density). This may yield a bias in the actual and average exposure population which can vary along the day (e.g., high in urban areas during working hours, low after working hours). Second, the saturation values adopted for urban roads discarded the impacts of downstream intersections since segment-specific length was large. Since capacity is influenced by a downstream intersection in short segments, the incorporation of capacity models according to the traffic control operational characteristics (e.g., traffic light, conventional roundabouts, stopcontrolled intersections) would be useful. Third, the analysis of indicator based on one hour with no variations in turning split distributions among routes. This may not represent in deep the magnitude of each cost component. Thus, the analysis of different time periods (e.g., covering all $24 \mathrm{~h}$ of a week) would improve the quantification of each externality.

Future research will be mostly focused on the use of the upcoming $5 \mathrm{G}$ technologies to couple the traffic information with impacts modeling analysis and crowdsourcing technology for tuning real-time potential exposure values during different periods of the day. Testing of the developed sustainability indicator in metropolitan corridors with high traffic volumes and vehicle compositions variations, and population exposure could be useful to identify differences among traffic externalities. Furthermore, the incorporation and optimization of corridor-specific pricing strategies (e.g., pay tolls) on costs would also be addressed. "Although some external costs varied according to the population density from link to link, the sustainability indicator developed in this paper assumed an equal weight for all cost components which may not 
correspond for local authorities and road users' preferences. Such aspects must be considered during the development of sustainable indicator by defining a specific weight for each external cost.

\section{ACKNOWLEDGEMENTS}

The authors acknowledge the Portuguese Authority for Road Safety (ANSR) for providing the data and the support of TEMA - CENTRO 01-0145-FEDER-022083; Strategical Project UID/EMS/00481/2019-FCT (FCT-Portuguese Science and Technology Foundation); @CRUiSE project (PTDC/EMS-TRA/0383/2014), funded within Project 9471 - Reforçar a Investigação, o Desenvolvimento Tecnológico e a Inovação and supported by European Community Fund FEDER; MobiWise (P2020 SAICTPAC/0011/2015), co-funded by COMPETE2020, Portugal2020 Operational Program for Competitiveness and Internationalization ( $\mathrm{POCl}$ ), European Union's ERDF (European Regional Development Fund), and FCT; and CISMOB (PGI01611, funded by Interreg Europe Programme). This work was also financially supported by the project POCI-010145-FEDER-029463 (DICA-VE) and POCI-01-0145-FEDER-029679 (InFLOWence) funded by FEDER through COMPETE2020- Programa Operacional Competitividade e Internacionalização (POCI), and by national funds (OE), through FCT/MCTES. C. Sampaio also acknowledges the support of FCT for the Scholarship SFRH/BD/138746/2018. Thanks are due for the financial support to CESAM (UID/AMB/50017/2019), to FCT/MCTES through national funds, and the cofunding by the FEDER, within the PT2020 Partnership Agreement and Compete 2020. Finally, the cooperation of Toyota Caetano Auto S.A. is appreciated, which allowed the use of vehicles for data collection.

\section{REFERENCES}

Abou-Senna H, Radwan E, Westerlund K, Cooper CD. Using a traffic simulation model (VISSIM) with an emissions model (MOVES) to predict emissions from vehicles on a limited-access highway. Journal of the Air \& Waste Management Association 2013; 63: 819-831.

ANSR. Autoridade Nacional Segurança Rodoviária. Sinistralidade Rodoviária-Ano 2016. Annual Report (in Portuguese), 2017.

Anya AR, Rouphail NM, Frey HC, Liu B. Method and Case Study for Quantifying Local Emissions Impacts of Transportation Improvement Project Involving Road Realignment and Conversion to Multilane Roundabout. 92nd Annual Meeting, Transportation Research Board, Washington, DC, United States, Paper 13-5243 2013.

Bandeira J, Almeida TG, Khattak AJ, Rouphail NM, Coelho MC. Generating Emissions Information for Route Selection: Experimental Monitoring and Routes Characterization. Journal of Intelligent Transportation Systems 2013; 17: 3-17. 
Bandeira J, Fernandes P, Fontes T, Pereira S, Khattak A, Coelho MC. Exploring multiple ecorouting guidance strategies in a commuting corridor. International Journal of Sustainable Transportation 2018a; 12: 53-65.

Bandeira J, Guarnaccia C, Fernandes P, Coelho MC. Advanced Impact Integration Platform for Cooperative Road Use. International Journal of Intelligent Transportation Systems Research 2018b; 16: 1-15.

Bandeira JM, Pereira SR, Fontes T, Fernandes P, Khattak AJ, Coelho MC. An Eco-Traffic Management Tool. In: de Sousa JF, Rossi R, editors. Computer-based Modelling and Optimization in Transportation. Springer International Publishing, Cham, 2014, pp. 41-56.

Borrego C, Amorim JH, Tchepel O, Dias D, Rafael S, Sá E, et al. Urban scale air quality modelling using detailed traffic emissions estimates. Atmospheric Environment 2016; 131: 341-351.

Borrego C, Lopes M, Cascão P, Amorim J, Martins H, Tavares R, et al. Urban air quality models. In: Chrysoulakis N, Castro E, Moors E, editors. Understanding urban metabolism: a tool for urban Planning. Routledge, UK, 2014, pp. p. 79-90.

Borrego C, Martins JM, Lemos S, Guerreiro C. A second generation Gaussian dispersion model: the POLARIS model. International Journal of Environment and Pollution 1997; 8: 789-795.

Cecchel S, Chindamo D, Turrini E, Carnevale C, Cornacchia G, Gadola M, et al. Impact of reduced mass of light commercial vehicles on fuel consumption, $\mathrm{CO} 2$ emissions, air quality, and socioeconomic costs. Science of The Total Environment 2018; 613-614: 409-417.

Chang T-H, Tseng J-S, Hsieh T-H, Hsu Y-T, Lu Y-C. Green transportation implementation through distance-based road pricing. Transportation Research Part A: Policy and Practice 2018; 111: 5364.

Chen G, Kauppila J. Global Urban Passenger Travel Demand and CO2 Emissions to 2050. Transportation Research Record: Journal of the Transportation Research Board 2017; 2671: 7179.

Ćirović $G$, Pamučar $D$, Božanić $D$. Green logistic vehicle routing problem: Routing light delivery vehicles in urban areas using a neuro-fuzzy model. Expert Systems with Applications 2014; 41: 4245-4258.

Coelho MC, Farias TL, Rouphail NM. Measuring and Modeling Emission Effects for Toll Facilities. Transportation Research Record 2005; 1941: 136-144.

Coelho MC, Fontes T, Bandeira JM, Pereira SR, Tchepel O, Dias D, et al. Assessment of potential improvements on regional air quality modelling related with implementation of a detailed methodology for traffic emission estimation. Science of The Total Environment 2014; 470-471: 127-137.

Coelho MC, Frey HC, Rouphail NM, Zhai H, Pelkmans L. Assessing methods for comparing emissions from gasoline and diesel light-duty vehicles based on microscale measurements. Transportation Research Part D: Transport and Environment 2009; 14: 91-99. 
Costa S, Ferreira J, Silveira C, Costa C, Lopes D, Relvas H, et al. Integrating Health on Air Quality Assessment-Review Report on Health Risks of Two Major European Outdoor Air Pollutants: PM and NO2. Journal of Toxicology and Environmental Health, Part B 2014; 17: 307-340.

Dias D, Amorim JH, Sá E, Borrego C, Fontes T, Fernandes P, et al. Assessing the importance of transportation activity data for urban emission inventories. Transportation Research Part D: Transport and Environment 2018; 62: 27-35.

EC. ExternE - Externalities of Energy Methodology 2005 Update: European Commission, Retrieved from: http://www.externe.info/externe_2006/, Acessed January 14, 2019, 2006.

EC. Roadmap to a Single European Transport Area - Towards a competitive and resource efficient transport system: European Comission, Retrieved from: https://ec.europa.eu/transport/sites/transport/files/themes/strategies/doc/2011_white_pape r/white-paper-illustrated-brochure_en.pdf, Acessed November 9, 2018, 2011.

EC. Multimodal Sustainable Transport: which role for the internalisation of external costs?: European Commission - Directorate-General for Transport and Mobility (DG MOVE), Retrieved from: https://ec.europa.eu/transport/sites/transport/files/2018-year-multimodality-externalcosts-note.pdf, Acessed March 21, 2019, 2018.

EEA. EMEP/EEA air pollutant emission inventory guidebook: Exhaust emissions from road transport., 2013.

EEA. Air quality in Europe - 2017 report. European Environment Agency, No 13/2017, Copenhagen, Denmark, 2017a, pp. 11.

EEA. Publications - Transport and Environment Reporting Mechanism (TERM): European Environmental Agency, Retrieved from: https://www.eea.europa.eu/downloads/00c37717c3e34479b874df54da0a2ac8/1532961615/ monitoring-progress-of-europes-transport.pdf, Acessed October 31, 2018, $2017 \mathrm{~b}$.

EEA. Air quality in Europe - 2018 report: European Environmental Agency, Retrieved from: https://www.eea.europa.eu/publications/air-quality-in-europe-2018, Acessed January 14, 2019, 2018a.

EEA. Population exposure to environmental noise. European Environment Agency, Retrieved from: https://www.eea.europa.eu/data-and-maps/indicators/exposure-to-and-annoyance-by2, Accessed March 20, 2018b.

El-Rashidy RAH, Grant-Muller SM. An operational indicator for network mobility using fuzzy logic. Expert Systems with Applications 2015; 42: 4582-4594.

EMISIA. COPERT Countries data: Retrieved from http://emisia.com/products/copert-data. Acessed May 16, 2017, 2017.

EPA. U.S. Transportation Sector Greenhouse Gas Emissions, 1990 -2016. : U.S. Environmental Protection Agency, Retrieved from: https://nepis.epa.gov/Exe/ZyPDF.cgi?Dockey=P100USI5.pdf Acessed October 31, 2018, 2018. 
ERSI. About ArcGIS | Mapping \&amp; Analytics Platform.: ERSI - Environmental Sistem Research Institute, Retrieved from: https://www.esri.com/en-us/arcgis/about-arcgis/overview, 2016.

ERSO. Annual Accident Report 2018: European Road Safety Observatory, Retrieved from: https://ec.europa.eu/transport/road_safety/sites/roadsafety/files/pdf/statistics/dacota/asr20 18.pdf, Accessed February 18, 2019, 2018.

Fernandes P, Fontes T, Neves M, Pereira SR, Bandeira JM, Rouphail NM, et al. Assessment of Corridors with Different Types of Intersections. Transportation Research Record: Journal of the Transportation Research Board 2015; 2503: 39-50.

Fernandes P, Teixeira J, Guarnaccia C, Bandeira JM, Macedo E, Coelho MC. The Potential of Metering Roundabouts: Influence in Transportation Externalities. Transportation Research Record 2018; 2672: 21-34.

Fontes T, Fernandes P, Rodrigues H, Bandeira JM, Pereira SR, Khattak AJ, et al. Are HOV/ecolanes a sustainable option to reducing emissions in a medium-sized European city? Transportation Research Part A: Policy and Practice 2014; 63: 93-106.

Fries R, Qi Y, Leight S. How Many Times Should I Run the Model? Performance Measure Specific Findings from VISSIM Models in Missouri. 96th Annual Meeting of the Transportation Research Board, Washington, DC, 2017.

Friesz TL, Bernstein D, Kydes N. Dynamic Congestion Pricing in Disequilibrium. Networks and Spatial Economics 2004; 4: 181-202.

Guarnaccia C. Advanced Tools for Traffic Noise Modelling and Prediction. WSEAS Transactions on Systems 2013; 12: 121-130.

HCM. Highway Capacity Manual, Sixth Edition: A Guide for Multimodal Mobility Analysis, Transportation Research Board, Washington DC, 2016.

Hu J, Frey HC, Washburn SS. Comparison of Vehicle-Specific Fuel Use and Emissions Models Based on Externally and Internally Observable Activity Data. Transportation Research Record 2016; 2570: 30-38.

IMT. Relatório de Tráfego na Rede Nacional de Auto-Estradas [In Portuguese]: Portuguese Institute for Mobility and Transport, Retrieved from: http://www.imtip.pt/sites/IMTT/Portugues/InfraestruturasRodoviarias/RedeRodoviaria/Relatrios/Relat\%C3\%B 3rio\%20de\%20Tr\%C3\%A1fego\%20-\%204\%C2\%BA\%20Trimestre\%20de\%202011.pdf, November 11, 2018, 2011.

IMT. Relatório de Tráfego na Rede Nacional de Auto-Estradas [In Poortuguese], Portuguese Institute for Mobility and Transport: Portuguese Institute for Mobility and Transport, Retrieved from:

http://www.imtip.pt/sites/IMTT/Portugues/InfraestruturasRodoviarias/RedeRodoviaria/Relatrios/Relat\%C3\%B 3rio\%20de\%20Tr\%C3\%A1fego\%20-\%204\%C2\%BA\%20Trimestre\%20de\%202018.pdf, April 8, 2019, 2019. 
Int Panis L, De Nocker L, Cornelis E, Torfs R. An uncertainty analysis of air pollution externalities from road transport in Belgium in 2010. Science of The Total Environment 2004; 334-335: 287298.

Jovanović AD, Pamučar DS, Pejčić-Tarle S. Green vehicle routing in urban zones - A neuro-fuzzy approach. Expert Systems with Applications 2014; 41: 3189-3203.

Khan T, Frey HC. Comparison of real-world and certification emission rates for light duty gasoline vehicles. Science of The Total Environment 2018; 622-623: 790-800.

Kickhöfer B, Kern J. Pricing local emission exposure of road traffic: An agent-based approach. Transportation Research Part D: Transport and Environment 2015; 37: 14-28.

Kickhöfer B, Nagel K. Towards High-Resolution First-Best Air Pollution Tolls. Networks and Spatial Economics 2016; 16: 175-198.

Korzhenevych A, Dehnen N, Bröcker J, Holtkamp M, Meier H, Gibson G, et al. Update of the Handbook on External Costs of Transport - Final Report, 2014.

Liu H, Gegov A, Cocea M. Unified Framework for Control of Machine Learning Tasks Towards Effective and Efficient Processing of Big Data. In: Pedrycz W, Chen S-M, editors. Data Science and Big Data: An Environment of Computational Intelligence. Springer International Publishing, Cham, 2017, pp. 123-140.

National Academies of Sciences E, and Medicine 2018,. Critical Issues in Transportation 2019. Networks and Spatial Economics, 2018, pp. 45.

Pamučar D, Gigović L, Ćirović $G$, Regodić $M$. Transport spatial model for the definition of green routes for city logistics centers. Environmental Impact Assessment Review 2016a; 56: 72-87.

Pamucar D, Goran Ćirović G. Vehicle route selection with an adaptive neuro fuzzy inference system in uncertainty conditions Decision Making: Applications in Management and Engineering 2018; 1: 13-37.

Pamučar D, Ljubojević S, Kostadinović $D$, Đorović $B$. Cost and risk aggregation in multi-objective route planning for hazardous materials transportation-A neuro-fuzzy and artificial bee colony approach. Expert Systems with Applications 2016b; 65: 1-15.

PTV AG. PTV VISSIM 9 User Manual: Planung Transport Verkehr AG, Karlsruhe, Germany, 2016. Quartieri J, lannone G, Guarnaccia C. On the Improvement of Statistical Traffic Noise Prediction Tools. 11th WSEAS Int. Conf. on Acoustics \& Music: Theory \& Applications, lasi, Romania, June 13-15, 2010, pp. 201-207.

Rivera F, Chamorro A, Lucero R, Aravena C. Development of Condition Indicator for Managing Sealed Rural Road Networks. Transportation Research Record: Journal of the Transportation Research Board 2015; 2474: 90-97.

Rückerl R, Schneider A, Breitner S, Cyrys J, Peters A. Health effects of particulate air pollution: A review of epidemiological evidence. Inhalation Toxicology 2011; 23: 555-592. 
Sampaio C, Bandeira JM, Macedo E, Vilaça M, Guarnaccia C, Friedrich B, et al. A Dynamic Linkbased Eco-indicator for supporting equitable traffic management strategies. Transportation Research Procedia 2019; 37: 43-50.

Sdoukopoulos A, Pitsiava-Latinopoulou M, Basbas S, Papaioannou P. Measuring progress towards transport sustainability through indicators: Analysis and metrics of the main indicator initiatives. Transportation Research Part D: Transport and Environment 2019; 67: 316-333.

Small KA, Verhoef ET. The Economics of Urban Transportation: Routledge, 2007.

Statistics of Portugal. Resident persons (No.) in family nuclei by Place of residence: Retrieved from: https://ine.pt. Accessed July 12, 2017, 2018.

Tafidis P, Sdoukopoulos A, Pitsiava-Latinopoulou M. Sustainable urban mobility indicators: policy versus practice in the case of Greek cities. Transportation Research Procedia 2017; 24: 304-312.

Torrao G, Fontes T, Coelho M, Rouphail N. Integrated indicator to evaluate vehicle performance across: Safety, fuel efficiency and green domains. Accident Analysis \& Prevention 2016; 92: 153167.

Turner S. Travel Time Data Collection Handbook: Office of Highway Information Management, Federal Highway Administration, U.S. Department of Transportation, 1998.

US EPA. Methodology for developing modal emission rates for EPA's multi-scale motor vehicle \& equipment emission system, 2002.

Valente J, Pimentel C, Tavares R, Ferreira J, Borrego C, Carreiro-Martins P, et al. Individual Exposure to Air Pollutants in a Portuguese Urban Industrialized Area. Journal of Toxicology and Environmental Health, Part A 2014; 77: 888-899.

Vasconcelos L, Seco A, Silva AB. Comparison of Procedures to Estimate Critical Headways at Roundabouts. Promet - Traffic and Transportation 2013; 25: 43-53.

Vicente B, Rafael S, Rodrigues V, Relvas H, Vilaça M, Teixeira J, et al. Influence of different complexity levels of road traffic models on air quality modelling at street scale. Air Quality, Atmosphere \& Health 2018; 11: 1217-1232.

Vlachokostas C, Achillas C, Moussiopoulos N, Kalogeropoulos K, Sigalas G, Kalognomou E-A, et al. Health effects and social costs of particulate and photochemical urban air pollution: a case study for Thessaloniki, Greece. Air Quality, Atmosphere \& Health 2012; 5: 325-334.

WHO. Burden of disease from environmental noise - Quantification of healthy life years lost in Europe: World Health Organization, Retrieved from: http://www.euro.who.int/_data/assets/pdf_file/0008/136466/e94888.pdf, Acessed February 2, 2019, 2011.

Winnie D, Christine B, Serge P. H. Traffic Simulation and Data: Validation Methods and Applications: CRC Press, Taylor \& Francis Group, Boca Raton, FL, 2014. 
Yeh C-F. Evaluation methods for external costs for road traffic based on objective territorialization in the metropolis. Cities 2013; 31: 76-84.

Yu M, Fan W. Calibration of microscopic traffic simulation models using metaheuristic algorithms. International Journal of Transportation Science and Technology 2017; 6: 63-77. 


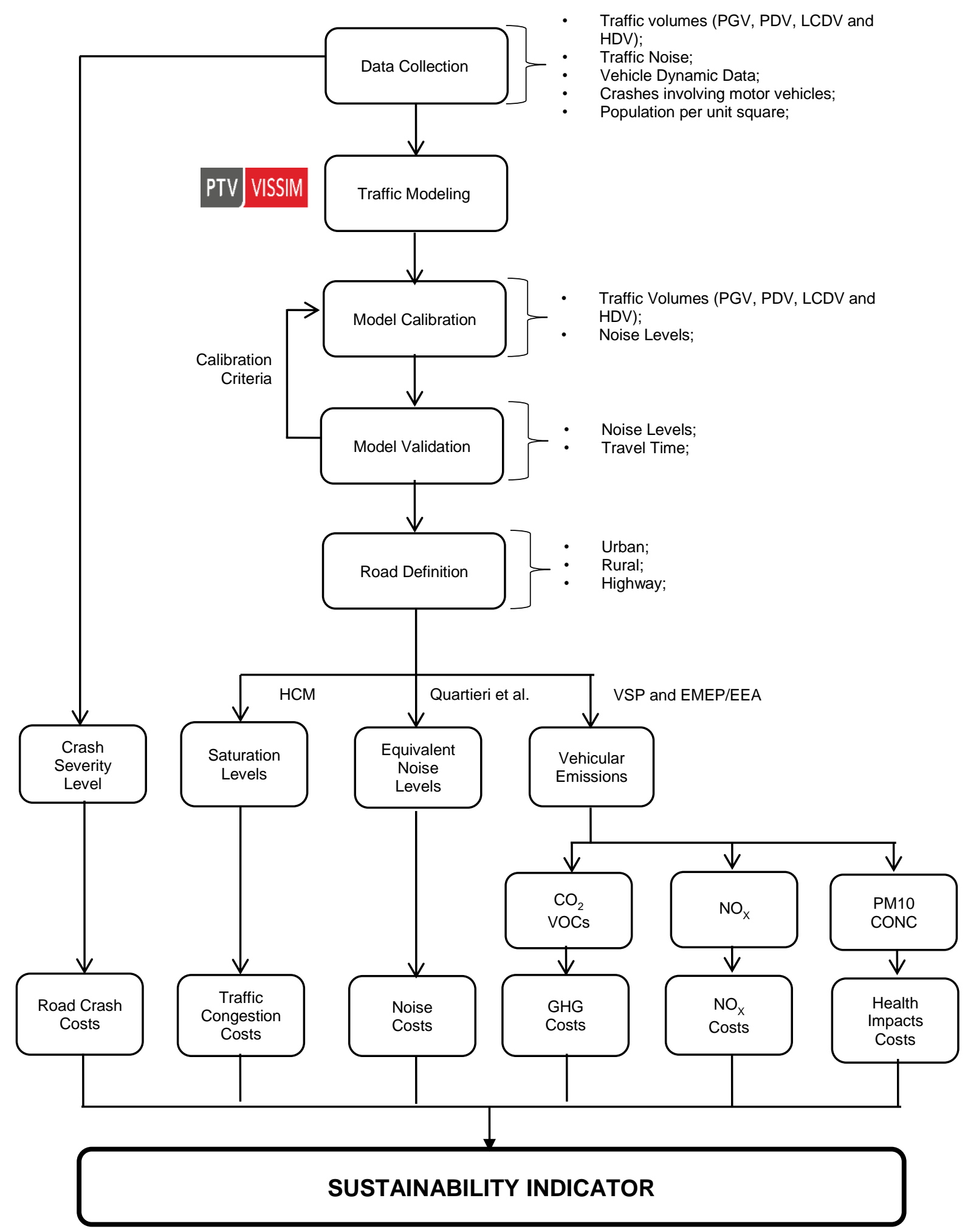

FIGURE 1 Overview of the research methodology (PGV - Passenger Gasoline Vehicles, PDV - Passenger Diesel Vehicles, LCDV - Light Commercial Diesel Vehicles; HDV - Heavy Duty Vehicles; HCM - Highway Capacity Manual; VSP Vehicle Specific Power; EMEP/EEA - European Monitoring and Evaluation Programme by European Environmental Agency; CONC - Concentrations). 
a)

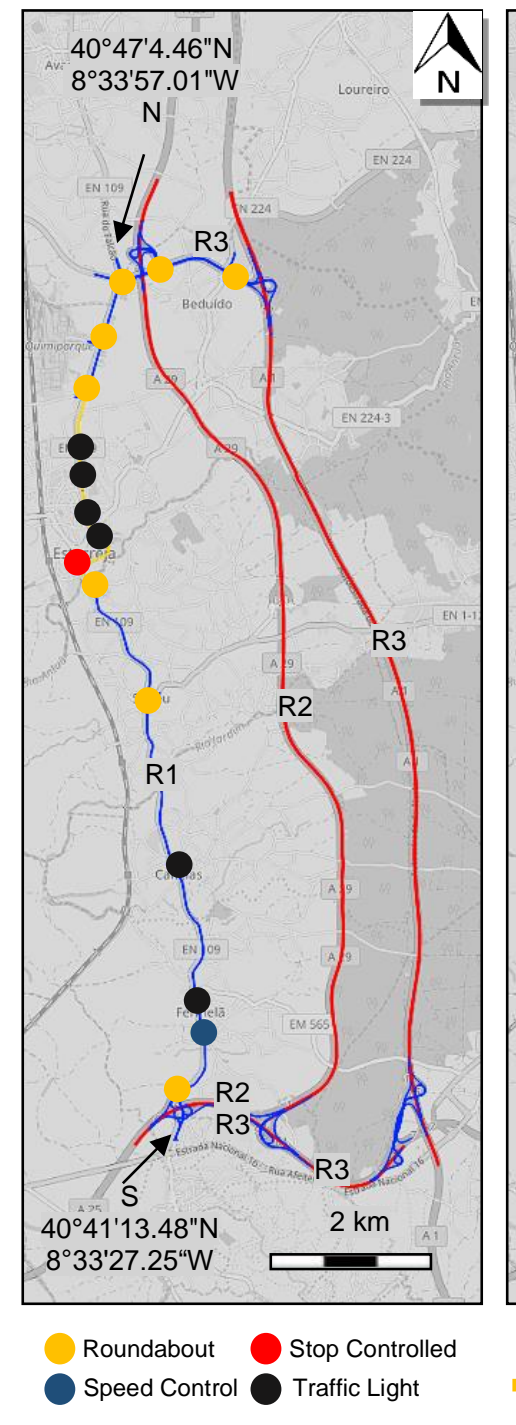

b)

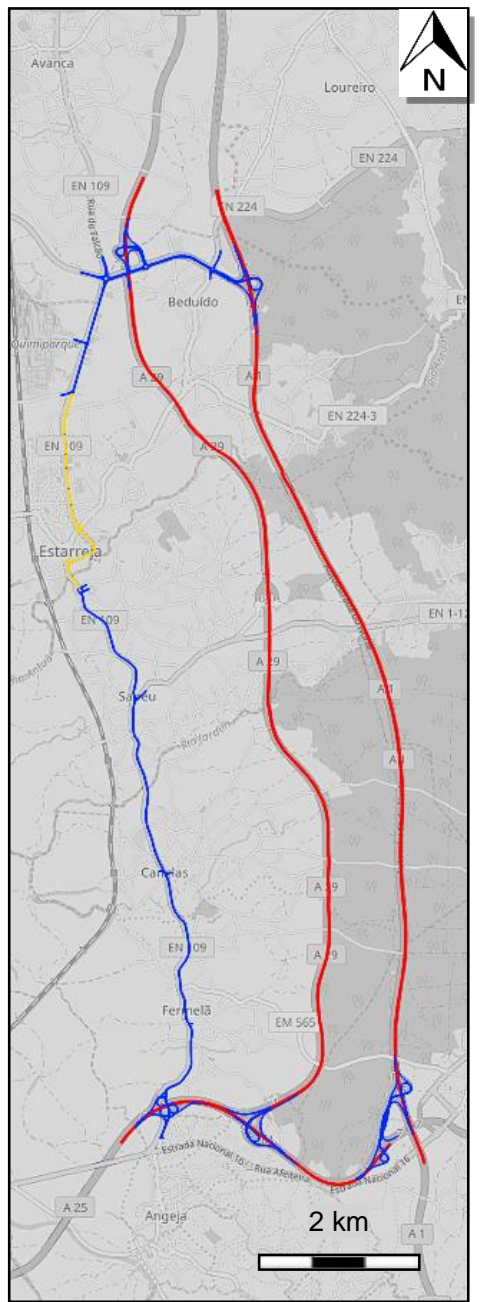

Urban Rural $\quad$ Highway c)

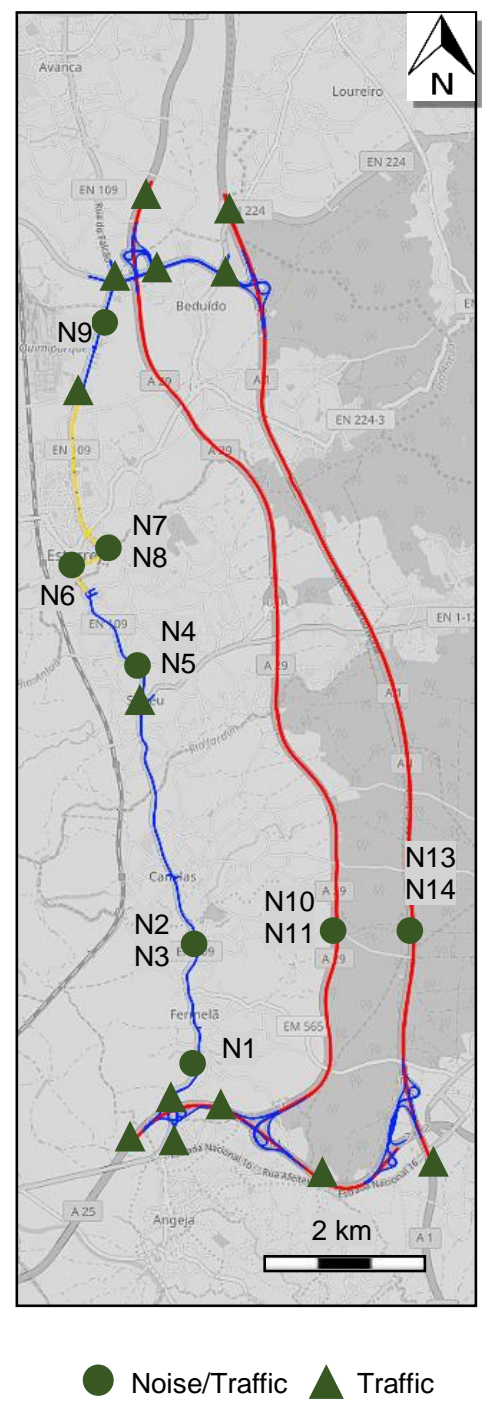

FIGURE 2 Study Domain: a) Routes Aerial View; b) Type of Road; c) Data Monitoring Points. Background Map Source [Open Street Maps]. 
a)

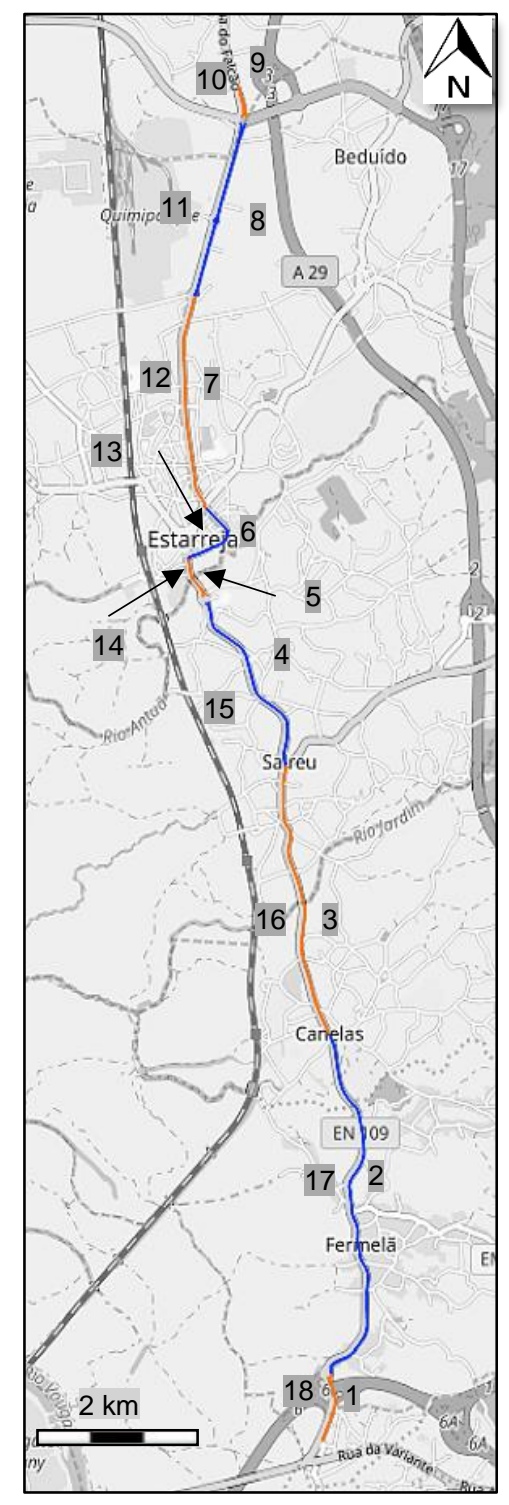

b)

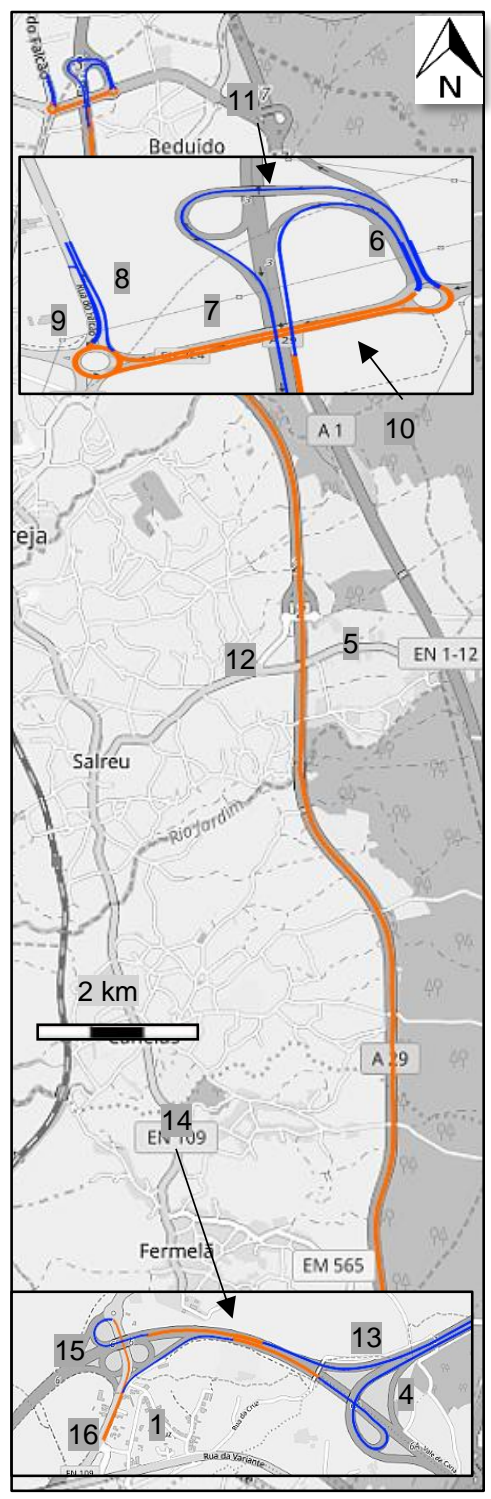

c)

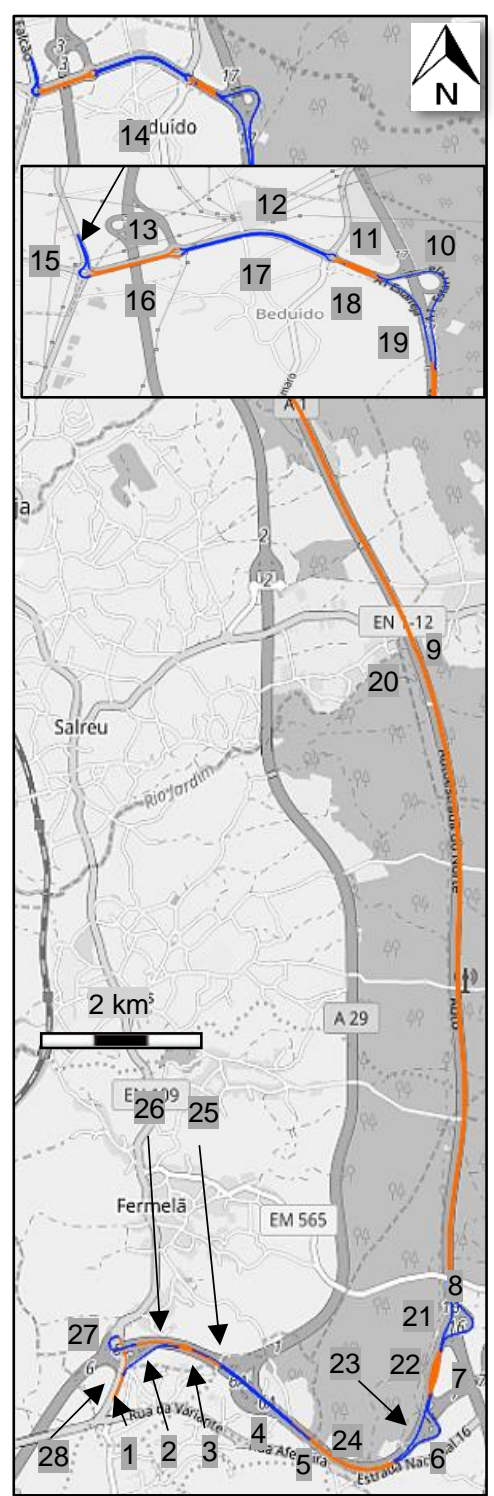

FIGURE 3 Segments definition by route: a) R1: b) R2; c) R3. Background Map Source [Open Street Maps]. 


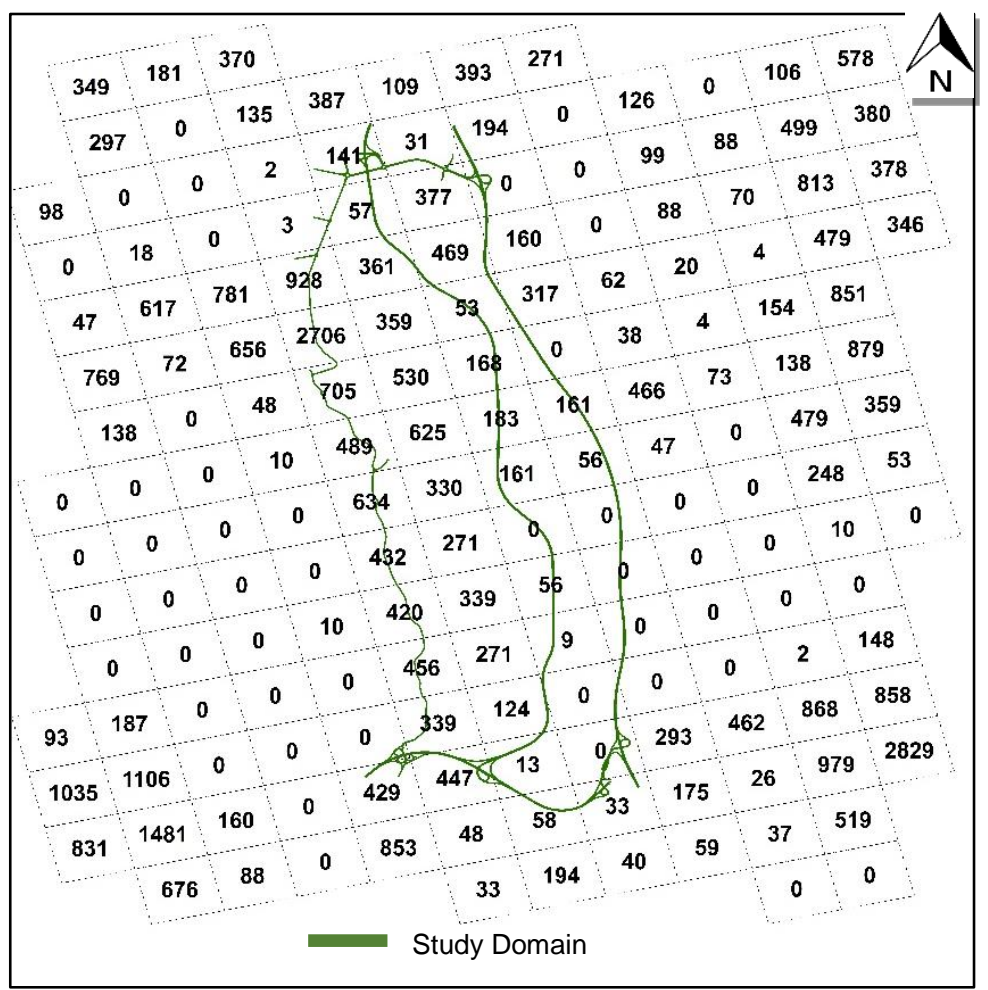

FIGURE 4 Local population density per square kilometer (Statistics of Portugal, 2018). Source [ArcGIS]. 


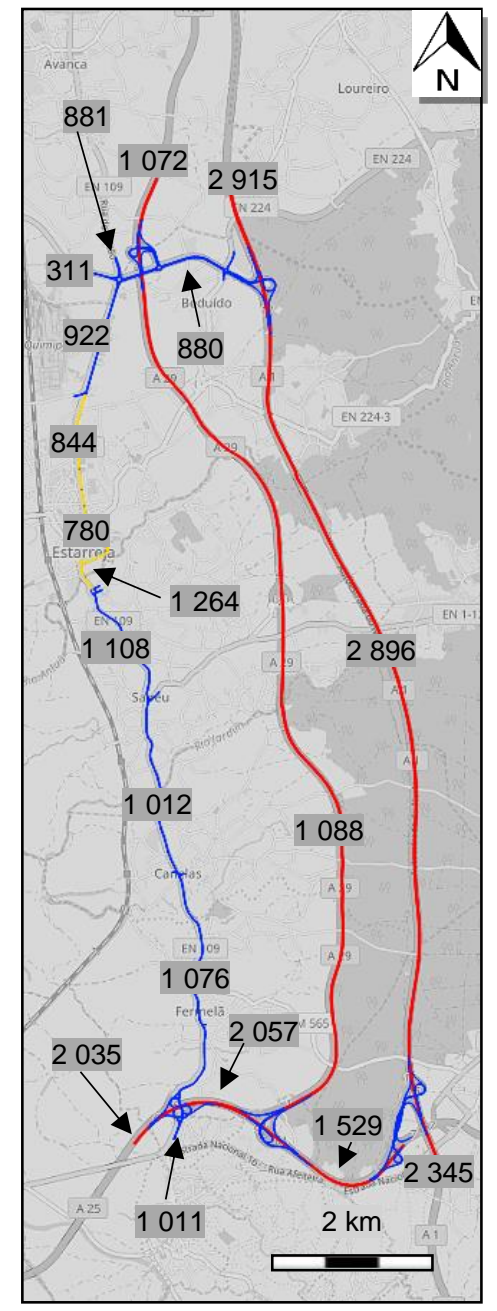

FIGURE 5 Traffic Volumes between 5:30-6:00PM. Background Map Source [Open Street Maps]. 
a)

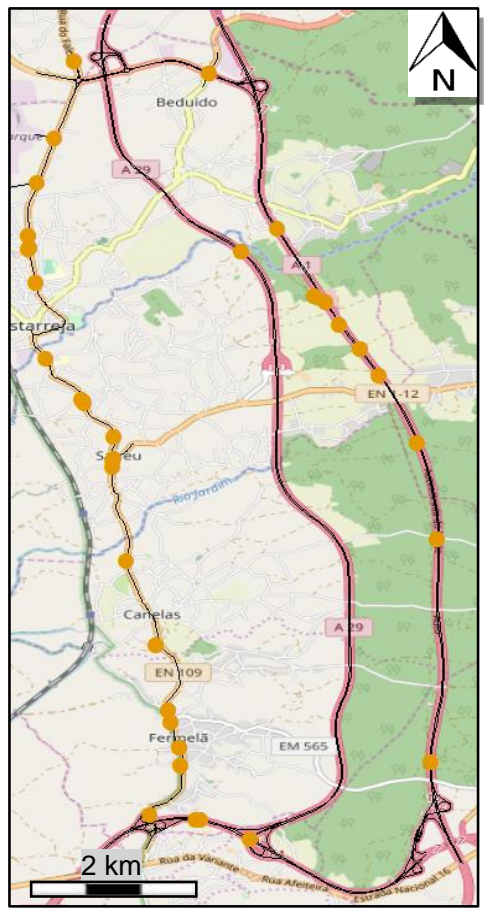

b)

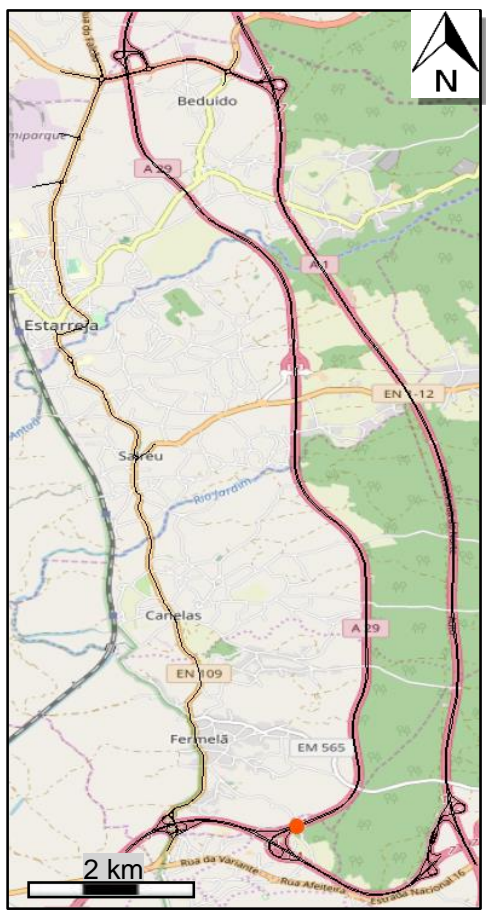

c)

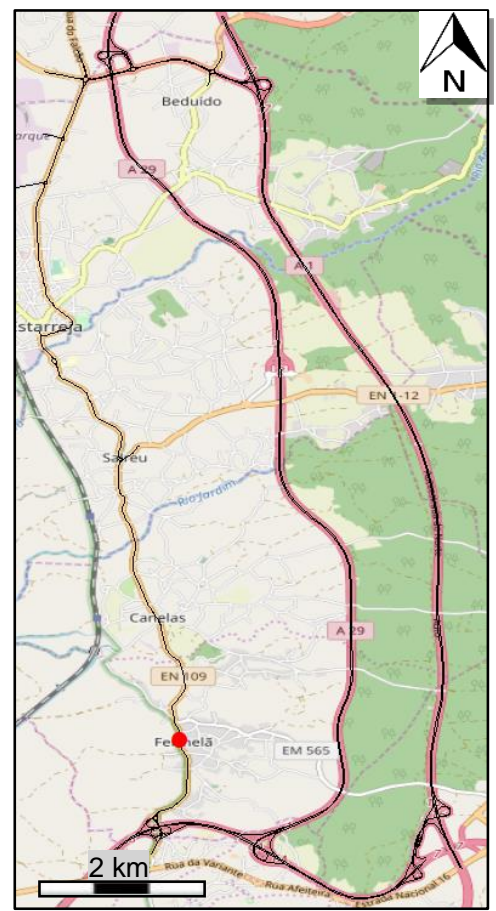

FIGURE 6 Spatial distribution of crashes based on level of injury severity: a) Light injury: b) Serious Injury; and c) Fatality. Background Map Source [Open Street Maps].

a)

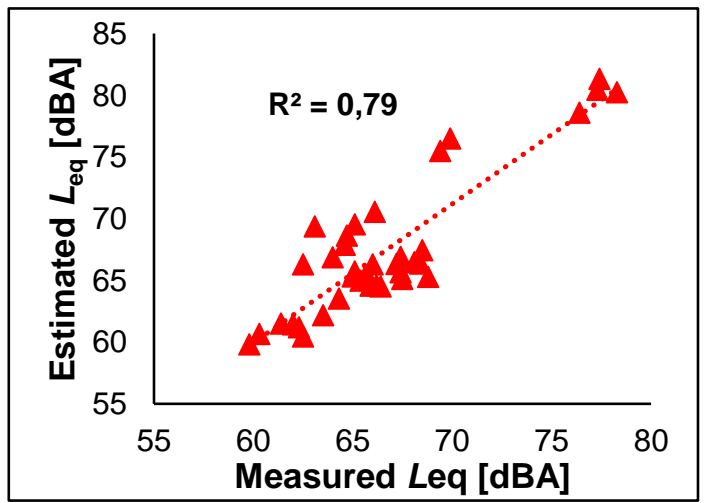

b)

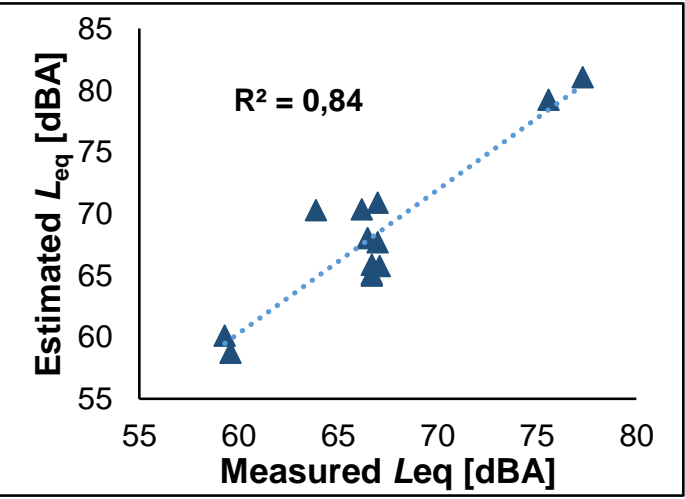

$\underline{\text { Note }}$ - $p$-value of F-test (ANOVA) performed in $R^{2}$ coefficient was 0 in both linear regression models, indicating statistical significance; estimated values were computed by adopting an average acoustic equivalent $(n)$ value of 8.

FIGURE 7 Noise methodology: a) Calibration; b) Validation. 
a)

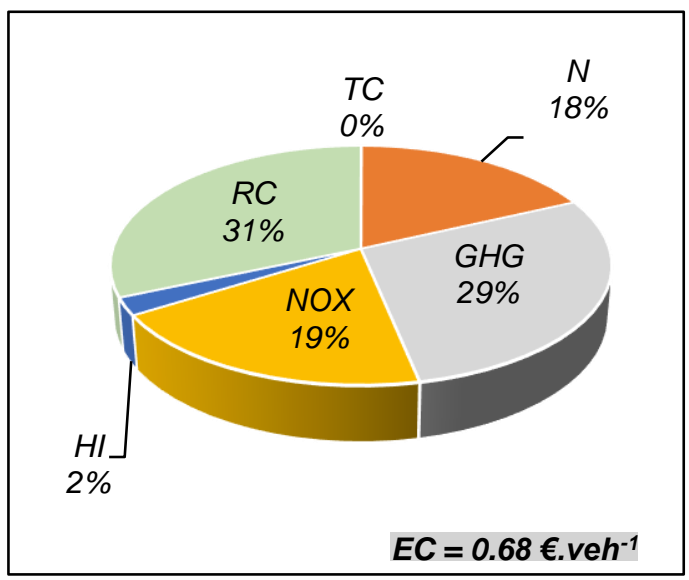

c)

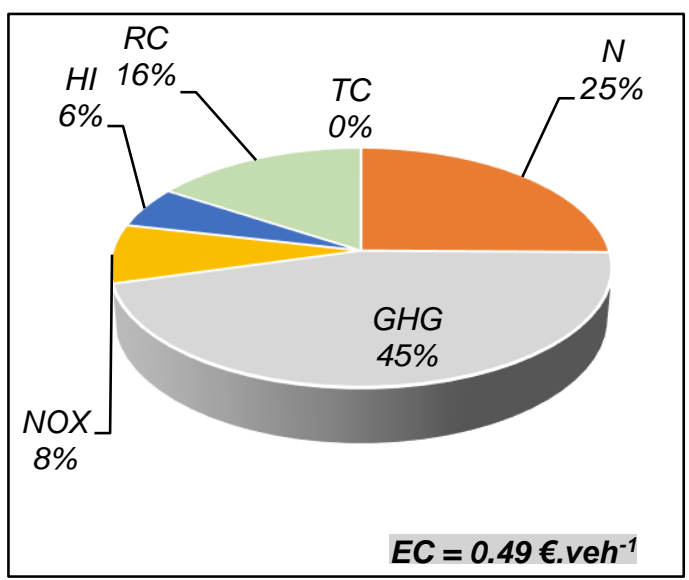

e)

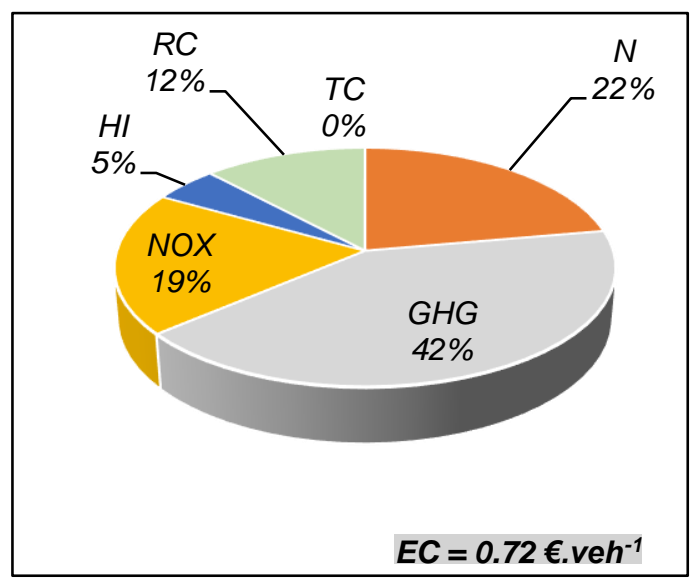

b)

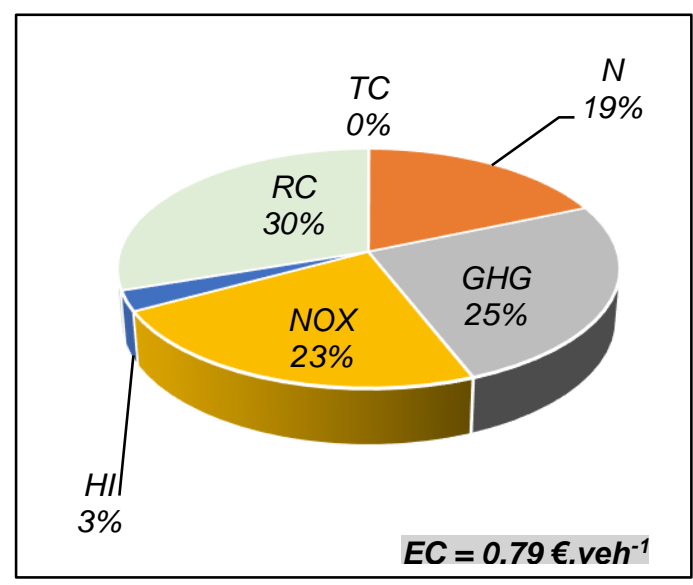

d)

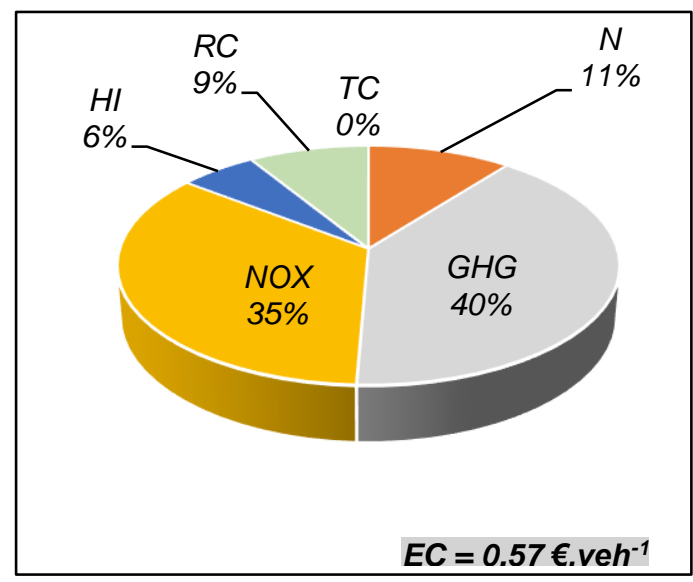

f)

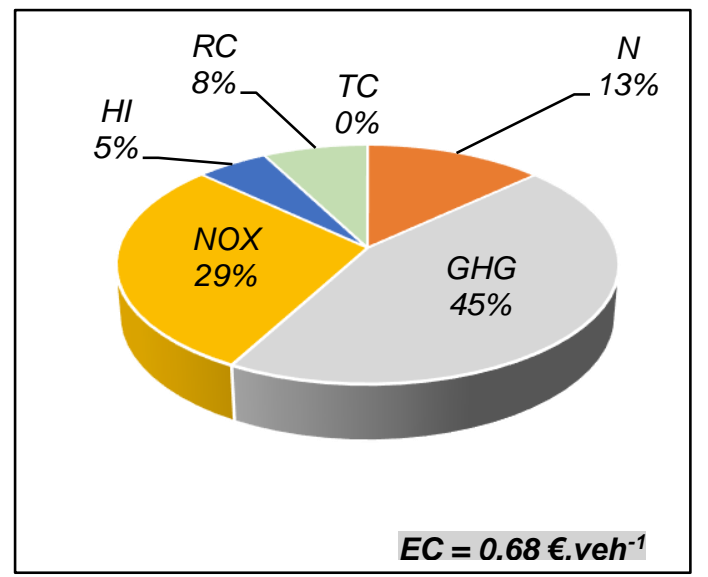

FIGURE 8 Distribution of external costs by route: a) South to North (R1); b) North to South (R1); c) South to North (R2); d) North to South (R2); e) South to North (R3); f) North to South (R3). 
a)

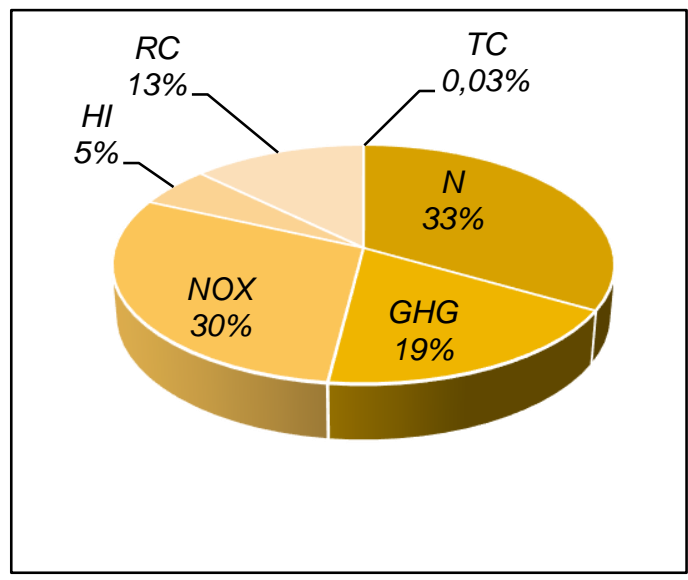

b)

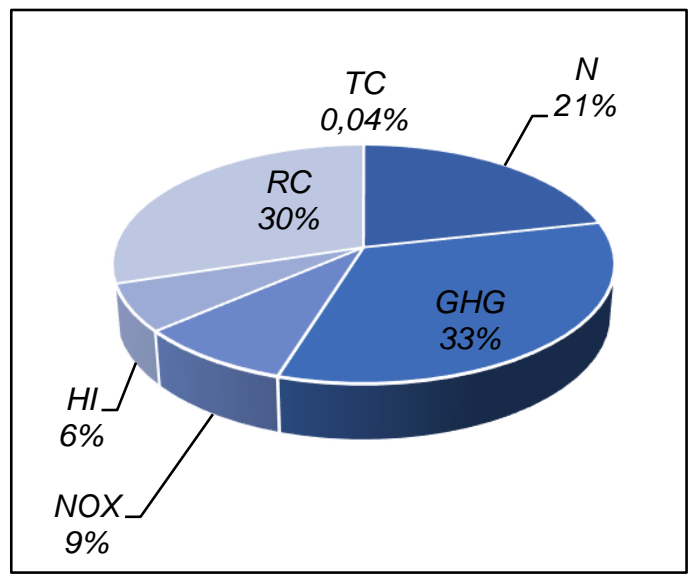

c)

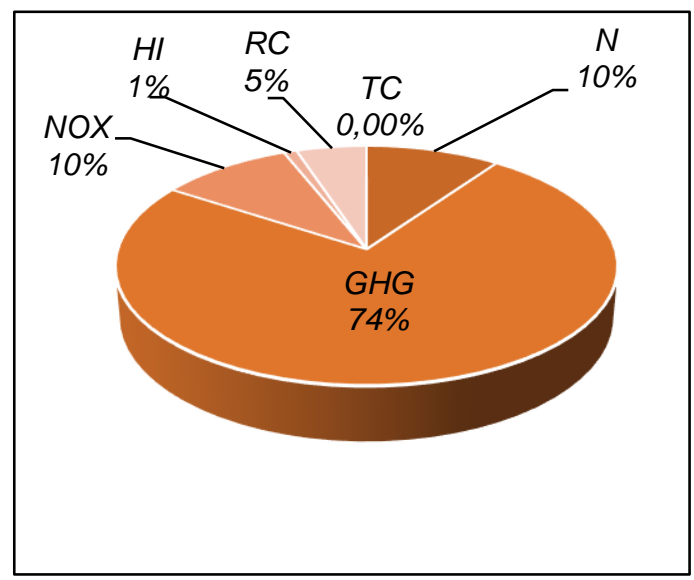

FIGURE 9 Distribution of external costs by type of road: a) urban; b) rural; c) highway. 
a)
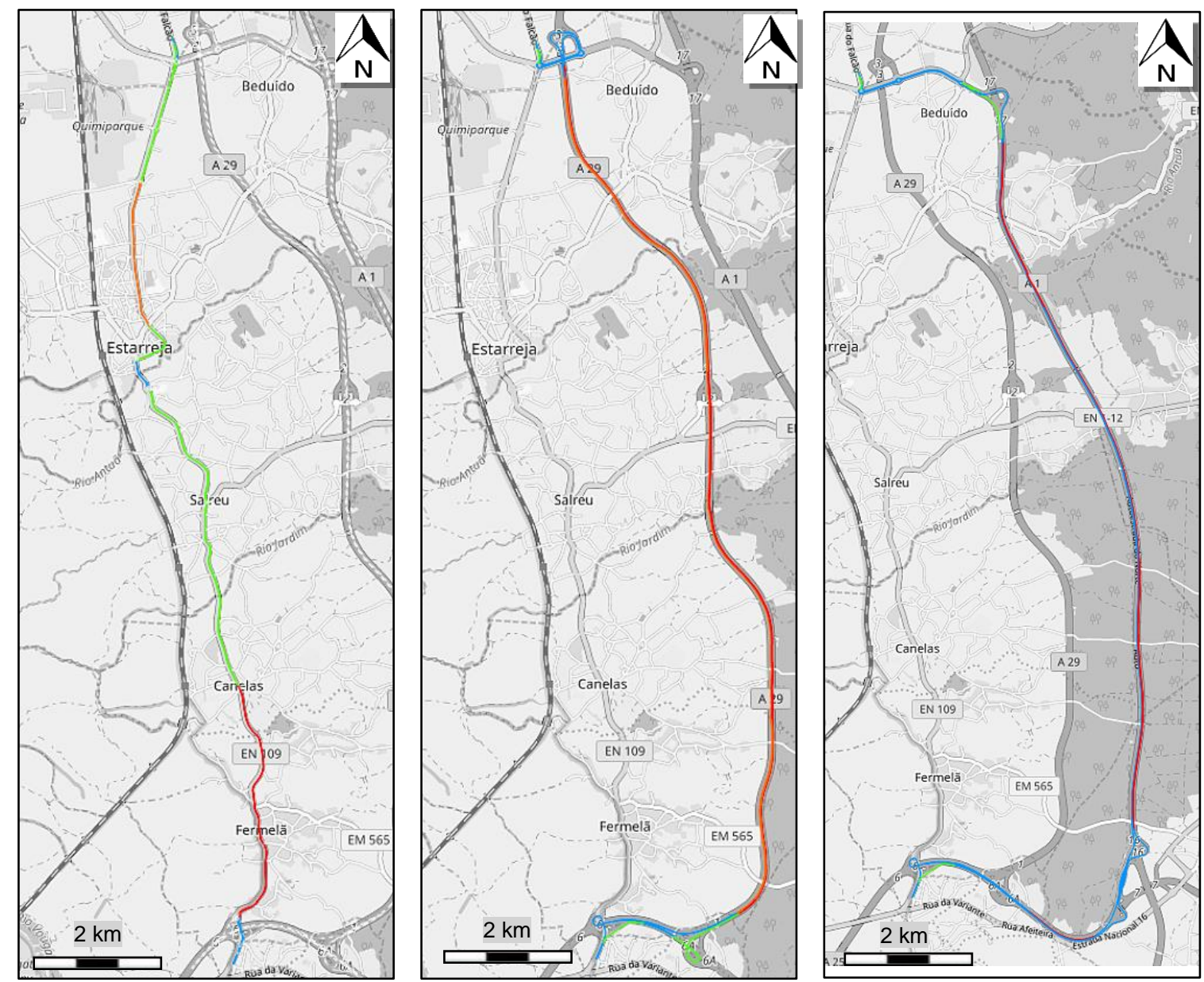

$T C_{k}<5 €$ ct.veh $^{-1}$ $5 €$ ct.veh ${ }^{-1}<T C_{k}<10 €$ ct.veh $10 €$ ct.veh ${ }^{-1}<T C_{k}<15 €$ ct.veh $^{-1}$ $T C_{k}>20 € c t . v e{ }^{-1}$

FIGURE 10 Distribution of external costs by route: a) R1; b) R2; and c) R3. 
TABLE 1 Key characteristics of proposed segments

\begin{tabular}{|c|c|c|c|c|c|c|}
\hline \multirow[b]{2}{*}{ Route } & \multicolumn{3}{|c|}{ South-North } & \multicolumn{3}{|c|}{ North-South } \\
\hline & $\begin{array}{c}\text { Segment } \\
\text { ID }\end{array}$ & $\begin{array}{c}\text { Type of } \\
\text { Road }\end{array}$ & $\begin{array}{c}\text { Length }^{a} \\
{[\mathrm{~km}]}\end{array}$ & $\begin{array}{c}\text { Segment } \\
\text { ID }\end{array}$ & $\begin{array}{c}\text { Type of } \\
\text { Road }\end{array}$ & $\begin{array}{c}\text { Length } \\
{[\mathrm{km}]}\end{array}$ \\
\hline \multirow{9}{*}{$\mathrm{R} 1$} & 1 & Rural & 0.56 & 10 & Rural & 0.33 \\
\hline & 2 & Rural & 2.97 & 11 & Rural & 1.45 \\
\hline & 3 & Rural & 2.23 & 12 & Urban & 1.72 \\
\hline & 4 & Rural & 1.59 & 13 & Urban & 0.69 \\
\hline & 5 & Urban & 0.35 & 14 & Urban & 0.34 \\
\hline & 6 & Urban & 0.69 & 15 & Rural & 1.59 \\
\hline & 7 & Urban & 1.73 & 16 & Rural & 2.23 \\
\hline & 8 & Rural & 1.51 & 17 & Rural & 2.97 \\
\hline & 9 & Rural & 0.26 & 18 & Rural & 0.53 \\
\hline \multirow{8}{*}{$\mathrm{R} 2$} & 1 & Rural & 0.22 & 9 & Rural & 0.33 \\
\hline & 2 & Rural & 0.56 & 10 & Rural & 0.49 \\
\hline & 3 & Highway & 0.41 & 11 & Rural & 1.03 \\
\hline & 4 & Rural & 1.49 & 12 & Highway & 10.90 \\
\hline & 5 & Highway & 11.00 & 13 & Rural & 1.06 \\
\hline & 6 & Rural & 0.64 & 14 & Highway & 0.50 \\
\hline & 7 & Rural & 0.47 & 15 & Rural & 0.38 \\
\hline & 8 & Rural & 0.26 & 16 & Rural & 0.53 \\
\hline \multirow{14}{*}{$\mathrm{R} 3$} & 1 & Rural & 0.22 & 15 & Rural & 0.33 \\
\hline & 2 & Rural & 0.56 & 16 & Rural & 0.49 \\
\hline & 3 & Highway & 0.41 & 17 & Rural & 1.03 \\
\hline & 4 & Highway & 0.96 & 18 & Rural & 0.86 \\
\hline & 5 & Highway & 0.83 & 19 & Rural & 0.66 \\
\hline & 6 & Rural & 0.85 & 20 & Highway & 9.49 \\
\hline & 7 & Rural & 0.99 & 21 & Rural & 0.60 \\
\hline & 8 & Rural & 0.75 & 22 & Rural & 0.89 \\
\hline & 9 & Highway & 9.48 & 23 & Rural & 0.58 \\
\hline & 10 & Rural & 1.10 & 24 & Highway & 1.04 \\
\hline & 11 & Rural & 0.56 & 25 & Highway & 1.03 \\
\hline & 12 & Rural & 0.89 & 26 & Highway & 0.50 \\
\hline & 13 & Rural & 0.47 & 27 & Rural & 0.38 \\
\hline & 14 & Rural & 0.26 & 28 & Rural & 0.53 \\
\hline
\end{tabular}

Note - a) Length by direction 
TABLE 2 Marginal cost factors for congestion according to the type of road (Korzhenevych et al., 2014)

\begin{tabular}{|c|c|c|c|c|c|}
\hline Parameter & $V / C$ & $L_{i}$ & $\begin{array}{c}\text { Urban } \\
(€ c t / v k m)\end{array}$ & $\begin{array}{c}\text { Rural } \\
(€ c t / v k m)\end{array}$ & $\begin{array}{l}\text { Highway } \\
\text { (€ct/vkm) }\end{array}$ \\
\hline \multirow{5}{*}{ CLDV } & 0 & 1 & 0.0 & 0.0 & 0.0 \\
\hline & 0.25 & 2 & 0.0 & 0.0 & 0.0 \\
\hline & 0.5 & 3 & 0.0 & 0.0 & 0.0 \\
\hline & 0.75 & 4 & 3.8 & 1.4 & 1.0 \\
\hline & 1 & 5 & 5.9 & 4.7 & 2.4 \\
\hline \multirow{5}{*}{$C_{\mathrm{HDV}}$} & 0 & 1 & 0.1 & 0.1 & 0.0 \\
\hline & 0.25 & 2 & 0.1 & 0.1 & 0.0 \\
\hline & 0.5 & 3 & 0.1 & 0.1 & 0.0 \\
\hline & 0.75 & 4 & 7.2 & 2.7 & 2.0 \\
\hline & 1 & 5 & 11.2 & 9.0 & 4.6 \\
\hline
\end{tabular}

TABLE 3 Marginal cost factors for noise exposure (Korzhenevych et al., 2014)

\begin{tabular}{cc}
\hline $\begin{array}{c}L_{\text {den, } \boldsymbol{k}} \\
(\mathbf{d B A})\end{array}$ & $\begin{array}{c}C L_{\text {den, } \boldsymbol{k}} \\
(\boldsymbol{\epsilon} / \mathrm{dBA} \text { per person and per } \\
\text { year) }\end{array}$ \\
\hline 51 & 6 \\
55 & 29 \\
60 & 56 \\
65 & 84 \\
70 & 113 \\
75 & 187 \\
\hline
\end{tabular}

$\underline{\text { Note }-V a l u e s ~ w i t h i n ~ t h r e s h o l d ~ i n t e r v a l s ~ a r e ~ c o m p u t e d ~ u s i n g ~ l i n e a r ~ i n t e r p o l a t i o n ~}$

TABLE 4 Summary of Calibration and validation of travel times

\begin{tabular}{ccccc}
\hline Model & Route & $\begin{array}{c}\text { Observed } \\
\text { Travel Time [s] }\end{array}$ & $\begin{array}{c}\text { Simulated } \\
\text { Travel Time [s] }\end{array}$ & p-value \\
\hline & $\mathrm{N} \rightarrow \mathrm{S}(\mathrm{R} 1)$ & $984 \pm 57$ & $992 \pm 50$ & 0.78 \\
& $\mathrm{~S} \rightarrow \mathrm{N}(\mathrm{R} 1)$ & $965 \pm 64$ & $987 \pm 28$ & 0.85 \\
Calibrated & $\mathrm{N} \rightarrow \mathrm{S}(\mathrm{R} 2)$ & $605 \pm 44$ & $631 \pm 31$ & 0.13 \\
(Training Set) & $\mathrm{S} \rightarrow \mathrm{N}(\mathrm{R} 2)$ & $589 \pm 39$ & $606 \pm 16$ & 0.26 \\
& $\mathrm{~N} \rightarrow \mathrm{S}(\mathrm{R} 3)$ & $732 \pm 29$ & $745 \pm 38$ & 0.37 \\
& $\mathrm{~S} \rightarrow \mathrm{N}(\mathrm{R} 3)$ & $760 \pm 32$ & $784 \pm 33$ & 0.11 \\
\hline & $\mathrm{N} \rightarrow \mathrm{S}(\mathrm{R} 1)$ & $968 \pm 67$ & $950 \pm 23$ & 0.58 \\
& $\mathrm{~S} \rightarrow \mathrm{N}(\mathrm{R} 1)$ & $997 \pm 124$ & $1,018 \pm 23$ & 0.69 \\
Validated & $\mathrm{N} \rightarrow \mathrm{S}(\mathrm{R} 2)$ & $585 \pm 23$ & $620 \pm 14$ & 0.16 \\
(Testing Set) & $\mathrm{S} \rightarrow \mathrm{N}(\mathrm{R} 2)$ & $611 \pm 15$ & $608 \pm 14$ & 0.76 \\
& $\mathrm{~N} \rightarrow \mathrm{S}(\mathrm{R} 3)$ & $752 \pm 20$ & $758 \pm 26$ & 0.73 \\
& $\mathrm{~S} \rightarrow \mathrm{N}(\mathrm{R} 3)$ & $760 \pm 4$ & $608 \pm 18$ & 0.10 \\
\hline
\end{tabular}

Note: $N \rightarrow S$ North to South; $S \rightarrow N$ South to North 